
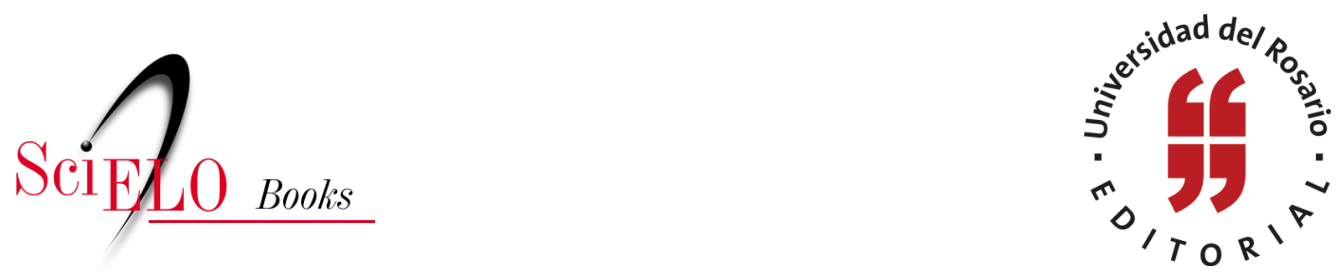

\title{
I. Educación jurídica en Iberoamérica y educación legal clínica
}

\author{
Beatriz Londoño Toro
}

\section{SciELO Books / SciELO Livros / SciELO Libros}

LODOÑO TORO, B. Educación jurídica en Iberoamérica y educación legal clínica. In: Educación legal clínica y litigio estratégico en Iberoamérica [online]. Bogotá: Editorial Universidad del Rosario, 2015, pp. 9-79. Textos de jurisprudencia collection. ISBN 978-958-738-624-0. https://doi.org/10.7476/9789587386240.0002.

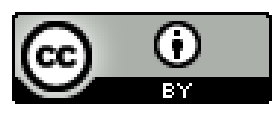

All the contents of this work, except where otherwise noted, is licensed under a Creative Commons Attribution 4.0 International license.

Todo o conteúdo deste trabalho, exceto quando houver ressalva, é publicado sob a licença Creative Commons Atribição 4.0.

Todo el contenido de esta obra, excepto donde se indique lo contrario, está bajo licencia de la licencia Creative Commons Reconocimento 4.0. 


\section{Educación jurídica en Iberoamérica y educación legal clínica}

\section{A. Los principales interrogantes de la educación jurídica en Iberoamérica}

La educación jurídica tradicional en Iberoamérica ha sido marcada por problemas graves que en siglos pasados no fueron tan evidentes pero que desde comienzos del siglo $\mathrm{xx}$ han generado multitud de trabajos y propuestas, en su mayoría elaboradas por docentes universitarios.

En el último decenio se han realizado esfuerzos académicos, institucionales e informes de organismos intergubernamentales y no gubernamentales, en los que las preocupaciones se centran en aspectos como la incidencia del formalismo jurídico en la formación dogmática de los abogados, los problemas metodológicos en la educación jurídica, la desconexión entre la teoría y la realidad social enfocada como responsabilidad social universitaria, y además se examinan las graves ausencias en temas vitales como la ética profesional, la investigación y la internacionalización, entre otros aspectos que muestran la gran crisis en la forma como se educan los abogados. A continuación se profundizará no solo en los problemas centrales, sino en las alternativas que están en construcción para intentar superarlos o mitigarlos.

\section{El formalismo jurídico. ¿Qué propuestas se construyen para superarlo?}

En los programas de derecho de Iberoamérica, el estudio de la ley en sentido formal, la mitificación de la separación de poderes, la separación entre derecho y política y la equiparación de validez formal con justicia continúan siendo los ejes de las preocupaciones pedagógicas que se repiten de generación en generación (Bonilla, p. 274).

Este modelo se refleja en la educación en muchos aspectos, como el protagonismo exclusivo del profesor, la relación vertical con los alumnos, el papel pasivo de estos, la memorización y el enciclopedismo como única exigencia, y los diseños curriculares extensos y derivados de una mirada exclusivamente 
legislativa (Minagawa, 2012). Se trata de una "educación bancaria”, en términos de Freire (1999).

Se considera que en las aulas de derecho, la formación jurídica es fragmentada y reproduce formas de pensar que dificultan la integración de los contenidos y la vida real, los casos prácticos o problemáticas específicas. De esta forma el nivel de significatividad es también escaso (Minagawa, 2012, p. 61). "Se ha verificado que el sistema de enseñanza tradicional tiene una deficiencia: no integra el plano teórico con el plano práctico de la profesión, imposibilitando el desarrollo de las habilidades necesarias para ese óptimo desempeño profesional posterior anhelado"(Guevara-Paredes, 2005,p. 146).

Esta realidad se relaciona directamente con la visión de la metodología de la educación jurídica que se utiliza, en la que prevalecen la exposición y la exposición dialogada, y son escasos los vínculos entre teoría y práctica. Como lo señala Bonilla, los abogados recién graduados "se enfrentan con serias dificultades para poner en práctica el arsenal de categorías jurídicas aprendidas en la universidad" (p. 263).

Los resultados de estos procesos de formación dejan mucho que desear en las sociedades latinoamericanas y se relacionan directamente con el estereotipo de abogado que identifica la gente como un profesional que solo tiene relación con sus clientes y cuya labor nunca se orienta hacia la sociedad; como un profesional que defiende intereses privados o particulares, pero al que le es ajeno el interés público.

Las propuestas de cambios en la enseñanza-aprendizaje del derecho implican reflexión sobre cómo se asumen al interior de las facultades de derecho los cambios en el sistema educativo. Son tres las más significativas transformaciones que se han comenzado a evidenciar: "a) cambios en el enfoque del proceso de enseñanza-aprendizaje: del énfasis en la enseñanza al aprendizaje; b) cambios en los contenidos objeto de aprendizaje y de evaluación; c) cambios en la evaluación" (García Añón, 2013b, p. 17).

En muchas ocasiones se ha reafirmado la importancia de un "diálogo entre el conocimiento legal y el conocimiento pedagógico” (Seda, 2012, p. 19) y la necesidad de repensar muchas de las prácticas pedagógicas que se realizan en la educación jurídica iberoamericana.

En primer lugar debemos considerar la incorporación de nuevas formas de enseñanza del derecho. Se parte de la pregunta más simple pero retadora para quienes asumen la labor docente e investigativa en los programas de 
derecho y para quienes lideran procesos de reforma curricular, que implican también la inquietud referida: ¿tiene el derecho una característica específica que condicione su forma de enseñanza?

El derecho aporta por sí mismo una herramienta pedagógica de enorme valor: se trata de la indagación a través de la resolución de casos, las posibilidades de un debate teórico riguroso con preguntas originales, el aporte que puede hacerse a través de la elaboración de proyectos de normas o políticas públicas, en fin, las aulas jurídicas deberían ser verdaderos laboratorios de ideas (Seda, 2006, p. 21).

En las facultades de derecho de las universidades iberoamericanas se ha identificado el grave problema de las formas de enseñanza desde fines del siglo XIX y comienzos del siglo pasado, y esta situación se acentúa por la resistencia al cambio en la comunidad académica. En el diagnóstico de Giner de los Ríos en España (1889), en los trabajos de docentes argentinos como Oliver en 1918 y Eduardo en 1939, y, en México, Rafael de Pina (1955), se hacía un llamado a modificar los métodos de la educación jurídica y se proponía incursionar en los estudios de caso y en la educación legal clínica.

El profesor García Añón trae una cita interesante de Giner de los Ríos, quien en el año 1889 realiza un diagnóstico que podría estar ubicado en nuestros días:

\begin{abstract}
Pues la reforma ha de tender a concluir, severamente y cuanto antes, con el carácter actual que hoy tiene entre nosotros esa enseñanza, y cuyas notas cardinales son: $1^{\text {a }}$ Formalismo mecánico, verbal y memorista con la trivialidad y superficialidad consiguientes. $2^{\text {a }}$ Pasividad del alumno, falto de iniciativa, de personalidad, trabajo e ideas propias, y, por tanto, de gusto e interés objetivo por la verdad científica. $3^{\mathrm{a}}$ Aislamiento, sequedad e incomunicación entre profesores y alumnos, y entre cada una de estas mismas clases (Giner de los Ríos, [1889] 2003, 42) (García Añón, 2013b, p. 33).
\end{abstract}

En los años sesenta se promovió un experimento pedagógico financiado por la Fundación Ford y con enormes recursos, que finalmente resultó un fracaso. Se trataba de un trasplante del modelo educativo de los Estados Unidos que buscaba cambiar el método de la cátedra magistral por la implementación del método socrático; el recurso pedagógico que se intentó fortalecer era el 
análisis de casos. Se difundió igualmente la idea del derecho como instrumento de cambio social y un cambio en la concepción del abogado y su papel en la sociedad (Rodríguez Garavito, 2006).

En las razones de este fracaso que se exponen se plantea por el profesor Rodríguez que los proyectos no tuvieron en cuenta la cultura jurídica de los países latinoamericanos en la que se pretendían instalar y además chocaban con intereses del sistema prevalente en América Latina. "En este sentido, fue muy importante el hecho de que la experiencia en América Latina mostró que los abogados estaban mucho menos comprometidos con el cambio social que lo que se había creído en un principio y que el derecho podía ser un poderoso mecanismo conservador del statu quo" (Rodríguez Garavito, 2006, p. 417).

El aprendizaje de este movimiento en América Latina y Colombia se socializó muy poco y simplemente se manejó como un gran fracaso. Sin embargo el experimento sirvió para una transformación de la teoría y el surgimiento y fortalecimiento de la corriente de critical legal studies (cLs). En América Latina surgieron también movimientos críticos denominados:

El derecho y el otro desarrollo, el desarrollo alternativo y el derecho alternativo, con aportes significativos en la revisión crítica.

De igual forma deben reconocerse cambios significativos en los contenidos y en la forma de mirar la educación jurídica. Evolucionamos de la memoria a la investigación, de la ley a la jurisprudencia, del silogismo a la ponderación, del procedimiento (medio) al efecto (resultado), del enciclopedismo a la asociación, del enriquecimiento personal a la responsabilidad social (Fajardo, 2012).

Otra de las propuestas para hacer frente a los problemas proviene de las teorías sobre formación en competencias dentro de los programas de derecho (Carreño, 2014). En los últimos años se ha priorizado la discusión sobre las competencias que se deben formar o fortalecer en los estudiantes de derecho y en dicho debate se destacan los aportes en relación con la formación ciudadana.

En su trabajo, la profesora Goyes plantea que las propuestas curriculares deben considerarse "orientaciones del quehacer educativo". Considera que en América Latina estas ideas buscan un replanteamiento de los énfasis educativos y pretenden superar lo puramente teórico intentando, desde unos 
modelos participativos en las instituciones educativas, un mayor compromiso con la ética del saber que a su vez involucra a los docentes, estudiantes y directivas (2012, p. 138).

Los currículos de las facultades de derecho en la región buscan cumplir con tres características señaladas por Damaska (1968): (i) gramática del derecho (conceptos); (ii) visión panorámica (estudio sistemático normativo y jurisprudencial) y (iii) enseñanza de la lógica interna del derecho (dogmáticaprincipios abstractos). Estas "se combinan en una educación reduccionista, legalista y memorística” (Montoya, s.f.).

La profesora Montoya se pregunta: ¿¿cómo incluir los temas de interés público en el currículo?:

La responsabilidad social de las universidades consiste en preparar a los estudiantes para decidir por sí mismos cómo resolver los conflictos entre lo individual y lo colectivo, entre lo jurídico y lo ético, entre lo legal y lo justo, cuando la vida profesional los ponga frente a esa ineludible necesidad. La relevancia social de los estudios de derecho en América Latina se medirá por la contribución social de la profesión jurídica al mejoramiento de las condiciones de justicia de la región. No debemos olvidar que en América Latina los abogados juegan un papel preponderante a pesar de que su educación no los haya preparado adecuadamente para responder a las necesidades imperiosas de una sociedad tan necesitada de líderes capaces no solo de pensar que un mundo más justo es posible, sino de hacerlo realidad (pp. 40-41).

El concepto de competencias se redefine, tal como lo propone el estudio Tuning para América Latina: "[...] el término competencias se ha re-significado y ahora se entiende como un proceso de formación integral del estudiante para lograr 'la combinación dinámica de conocimiento, comprensión, capacidades y habilidades" (Tuning, 2007).

Para el caso colombiano existe una propuesta de competencias específicas que deberían formarse en los programas de derecho y que fueron propuestas por Acofade (2011): (i) competencia cognitiva jurídica: hace referencia a la comprensión de principios y conceptos básicos, así como a las posibilidades de su aplicación; (ii) competencia comunicativa: tiene que ver con la capacidad de redactar, argumentar e interpretar, así como con la iniciativa para buscar solu- 
ciones a problemas jurídicos que se plantean; (iii) competencia jurídica para prevenir e intervenir en un conflicto utilizando mecanismos adecuados; (iv) competencia investigativa jurídica: relacionada con el proceso de investigación científica para la solución de problemas jurídicos; y (v) competencia ética y responsabilidad jurídica: "capacidad para identificar las conductas contrarias a la lealtad, la diligencia, y la transparencia propias del ejercicio profesional de la abogacía" (Goyes, 2012, p. 141).

Sobre esta propuesta, consideramos que constituye un avance y que en la práctica ya empieza a permear las facultades de derecho, desde el momento inicial de construcción de los programas para las asignaturas y en todo el proceso pedagógico. Los sistemas de evaluación que se están diseñando en el país también incluyen estas competencias específicas, aunque la realidad es que se trata de un aprendizaje institucional y colectivo.

El profesor Lidman considera en relación con el uso de habilidades y valores en la formación de los estudiantes de derecho que en cada país, de acuerdo al sistema jurídico que se tenga, se deben definir estas habilidades y valores, teniendo en cuenta la historia, la cultura propia y la realidad que se vive (2005, p. 83).

En Estados Unidos, por ejemplo, el informe MacCrate identificó diez habilidades principales y cuatro valores fundamentales en el nuevo perfil del abogado:

a) Habilidad para solucionar problemas.

b) Habilidad de análisis y razonamiento legales.

c) Habilidad para el planteamiento de la investigación legal.

d) Habilidad para la investigación efectiva (aplicativa).

e) Habilidad comunicativa.

f) Habilidad de asesoramiento.

g) Habilidad de negociación.

h) Habilidad sobre litigios y procedimientos alternativos para la resolución de conflictos.

i) Habilidad para la organización y gerencia del trabajo legal.

j) Habilidad para el reconocimiento y resolución de dilemas éticos.

A su vez, los valores fundamentales identificados en el estudio mencionado son los siguientes: 
1) Valor relacionado con la disposición o capacidad de una representación competente.

2) Valor orientado a promover la justicia, la imparcialidad y la moralidad

3) Valor orientado a esforzarse para mejorar la profesión de abogado

4) Valor para el desarrollo profesional auto-personal (Lidman, 2005, p. 84).

Observamos, desde una perspectiva crítica, cómo estas propuestas se centran en un enfoque meramente individual del ejercicio de la profesión de abogado. El siglo xxi exige abogados con competencias de trabajo colectivo y con competencias para comprender y desarrollar labores de alto impacto en la comunidad, entre las cuales el litigio estratégico, la labor de street law o pedagogía ciudadana, el conocimiento de los instrumentos mediáticos de difusión local, regional y global de los casos o acciones y el aprendizaje formativo que implica el trabajo en redes colaborativas pueden ser nuevas herramientas que con urgencia se deben aportar en las escuelas de derecho.

Como lo afirma González:

[...] una actividad clínica centrada en casos de interés público, esto es, casos que por su misma definición son de relevancia social y, casi invariablemente, de una complejidad alta desde el punto de vista jurídico (en la medida en que generalmente implicarán poner en tela de juicio la jurisprudencia predominante reuniendo argumentos para abrir paso a una nueva jurisprudencia), resultan especialmente apropiados para entrenar a los estudiantes en una serie de destrezas argumentativas y prácticas (González Morales, 2004, p. 40).

Existen competencias específicas que desarrollan las clínicas, como el razonamiento medio-fin para poner las normas al servicio de la sociedad; la identificación, diagnóstico y solución de problemas sociales; la estructuración de casos colectivos y la generación de soluciones alternativas, entre otras (Correa, 2013, p. 22).

Una competencia central en la labor del abogado de hoy es la capacidad de trabajo en equipo. Melisa Guevara-Paredes reconoce en su trabajo que los estudiantes y profesionales del derecho tienen grandes dificultades para 
relacionarse y trabajar en equipo y que esta sería una de las competencias que deberían fortalecer los programas (2005, p. 145).

Para reformular los métodos una buena propuesta se orientaría hacia la didáctica en grupos donde exista interacción e intercambio en los procesos de construcción de conocimiento. Los grupos son un medio muy eficaz para fortalecer los objetivos comunes, promover el trabajo colaborativo y permitir los aportes de los estudiantes. El reto se encuentra en el cambio de papel del docente, que se debe convertir en un orientador y mediador de espacios de aprendizaje y reflexión (Minagawa, 2012, p. 63).

Son innumerables los rasgos positivos de las nuevas propuestas pedagógicas y en ellas se evidencia la participación activa, la incorporación permanente de nuevos temas y contenidos aportados por los alumnos y profesores, el estímulo a la curiosidad e interés investigativo en los estudiantes, el desarrollo de nuevas habilidades valiosas para el ejercicio del derecho, el apoyo del grupo y la construcción colectiva de conocimiento. Los profesores pueden también efectuar un mejor seguimiento de los procesos de aprendizaje, generar un clima activo, fomentar el trabajo grupal docente, favorecer la articulación teoría-práctica y fortalecer las competencias investigativas (Minagawa, 2012, pp. 69-70).

Existe un movimiento interesante en torno a los temas de innovación académica propuestos desde el derecho (Fortunato, 2012, pp. 42-53). En el trabajo de compilación que realizó García Añón (2013a) se realiza un llamado a la innovación pedagógica en varios frentes: (i) incorporación del tema de definición, implementación y fortalecimiento de competencias genéricas y específicas en los programas de derecho; (ii) el sistema de calidad docente; (iii) la necesidad de avanzar en propuestas sobre guías teórico-prácticas, aprendizaje experiencial, método de casos, simulación, talleres interdisciplinarios, aprendizaje colaborativo y el aprendizaje basado en problemas; (iv) la realización de aproximaciones teóricas y de experiencias en educación legal clínica; (v) las nuevas tecnologías y su impacto en el aprendizaje; (vi) la enseñanza del derecho a través del cine y la literatura; vii) la evaluación del aprendizaje; (viii) la internacionalización de la docencia y el aprendizaje de los estudiantes a través de pasantías y (ix) la divulgación científica de la actividad docente.

En relación con el aprendizaje significativo, se considera que el mayor logro será que los estudiantes sean los protagonistas de su proceso de aprendizaje y cuenten con las herramientas que aporta la teoría y las posibilidades 
de aplicación de ese conocimiento en la búsqueda de solución a problemas de su entorno, con claridad en los valores que se forman y en la responsabilidad social que se asume desde los diversos actores de la academia (Goyes, 2013, p. 82).

Un complemento importante de la formación por competencias es el debate sobre la necesidad de redefinir los sistemas de evaluación. Este es un tema pendiente en las investigaciones latinoamericanas y muy especialmente en aquellas dirigidas a la educación legal clínica. Por evaluación entendemos aquel proceso que "apunta a la innovación y a la mejora y no a la comprobación; recupera la subjetividad y tiene como garantía el diálogo, la posibilidad de crítica y la circulación. Es una evaluación situada”, en la que los criterios deben ser explícitos (Di Matteo, 2012, p. 78).

\section{Desconexión entre la teoría y la realidad social}

El área de trabajo donde las universidades ubican a las clínicas y resaltan sus logros en informes y presentaciones es el área de extensión, concepto que hoy requiere de un debate más amplio, profundo y dotado del componente ético de todo lo que realizan los docentes y estudiantes. Al respecto ArmasAlvarado señala:

La proyección social está ayudando justamente, a que el sentido original de la universidad no perezca. Consideramos que la proyección social de la universidad hacia la comunidad, no es asistencialismo ni caridad.La universidad no juega el rol de "salvador" de la comunidad. Hay más bien un beneficio mutuo. Y es que con la proyección social, la universidad se beneficia de muchas formas.

Por un lado, la universidad no puede existir de espaldas a la realidad. Por el contrario, la universidad debe desarrollar su trabajo en función de la comunidad. Este contacto con la realidad que se posibilita gracias a la proyección social, le da a la universidad mejores herramientas para desarrollar su labor (2005, p. 141).

En esta materia resulta muy importante el trabajo comparado y el examen del concepto de proyección social desde las facultades de derecho, al entender que su finalidad es "materializar la contribución del derecho en el mejoramiento de las condiciones de vida de las personas o grupos de bajos ingresos 
o marginales a los beneficios del sistema legal”. (Ortiz-Sánchez, 2005, p. 29). Esa contribución se basa en tres premisas: (i) el acceso a la justicia y la participación ciudadana como prioridades para las universidades, (ii) la tipología de acciones de los estudiantes de derecho en la sociedad y (iii) el método de enseñanza basado en aprender en la realidad (2005, pp. 24-25).

En relación con la proyección social de las facultades de derecho, ella implica acciones concretas en el entorno y no un simple activismo. Se exige direccionar lo académico hacia la solución de problemas concretos de la comunidad, y cuando se abordan los problemas de acceso a la justicia se pueden encontrar, según el autor, tres manifestaciones de injusticia: injusticia estructural, injusticia social e injusticia particular ${ }^{2}$ (2005, p. 26).

La extensión es una de las funciones misionales de las universidades y son múltiples las discusiones y trabajos que se han realizado sobre su valor e impacto en la sociedad. Existen tres premisas relacionadas con la tarea de extensión universitaria, que para el análisis de la educación legal clínica son importantes:

a) El eje de las actividades de extensión universitaria está en la formación de los estudiantes y docentes que participan.

b) La intervención en el medio social debe estar determinada por la incorporación de dispositivos innovadores de docencia e investigación.

c) La difusión de derechos constituye una labor emancipatoria, siempre que se incorpore una interpretación dinámica de las normas y una perspectiva socio-histórica (Seda, 2012, p. 177).

Los impactos del trabajo de extensión son visibles y se reconocen por los estudiantes como fuente de nuevos conocimientos; aportan además a los contenidos de las asignaturas, modifican la metodología de enseñanza-aprendizaje y aportan destrezas en los estudiantes para interactuar con diversos grupos sociales, lo cual será de enorme utilidad en su futuro profesional.

\footnotetext{
2"Injusticia estructural: principios o derechos no reconocidos en las constituciones, inexistencia de órganos jurisdiccionales rápidos y efectivos. Injusticia social: discriminación sistemática, normas no recogidas en la legislación. Injusticia particular: actos de desconocimiento de derechos subjetivos legalmente reconocidos"(Ortiz-Sánchez, 2005, p. 28).
} 
Se concluye, de acuerdo con lo anterior, que es indispensable una nueva mirada de los currículos para "[...] insertar en ellos la integralidad del saber jurídico y superar la parcialización del conocimiento” (Goyes, 2013, p. 85).

Es igualmente urgente la relación de la universidad con la comunidad y con las organizaciones sociales; el rol de la investigación acción participativa, los consultorios o servicios de asistencia jurídica y las prácticas se tendría que fortalecer para lograrlo.

Al examinar la labor que realizan las clínicas jurídicas —o las estrategias para el litigio de alto impacto-, esta se correlaciona directamente con lo que podríamos denominar la caja de nuevas herramientas para los estudiantes de derecho, con aportes significativos en materia pedagógica, investigativa y social. En la educación legal clínica se fortalecen competencias y se motiva el aprendizaje basado en problemas reales y en la búsqueda de soluciones creativas.

Una pregunta interesante que surge a todos los que trabajan en temas de extensión y responsabilidad social universitaria plantea:

¿Es válido y ético usar los problemas de las personas para satisfacer las necesidades de enseñanza de las facultades de derecho? La respuesta, sin duda, es que si solamente diseñamos el servicio con ese objetivo no será ético. Sin embargo, creemos que ello dependerá de los objetivos y finalidades que se planteen las facultades cuando intervengan en las comunidades. Nosotros consideramos que sí es posible cumplir con ambos objetivos si se constituyen y actúan como interdependientes y estableciendo claramente cuáles son las prioridades y límites en dichos objetivos (Ortiz-Sánchez, 2005, p. 30).

En la educación legal clínica, esta pregunta surge en forma permanente. En el trabajo del profesor Abramovich se plantean las exigencias para el trabajo clínico con total respeto por los derechos de las personas que se representan, la exigencia de una relación horizontal y la contribución al fortalecimiento y empoderamiento de la comunidad a través de la causa que se adelanta:

Reconstruir la práctica de representar a gente sin recursos en causas de interés público requiere restablecer una relación igualitaria entre el abogado y el cliente, asumiendo el desafío de traducir un conflicto 
social en un caso judicial sin traicionar los rasgos característicos de ese conflicto ni la imagen de sus protagonistas [...]. El dilema puede definirse así: cómo mantener desde la posición elegida una relación adecuada con los grupos o sectores que procuramos representar, para que los casos seleccionados surjan de sus verdaderos intereses y conflictos, y sirvan para fortalecer y no para debilitar su organización y el desarrollo de sus luchas sociales.

Se trata de una dura impugnación de la práctica cotidiana de las clínicas legales de interés público, similar por su peso al cuestionamiento que la educación clínica presenta a la pedagogía tradicional de las facultades de derecho (Abramovich, 1999, p. 24).

\section{La brecha entre educación jurídica y derechos humanos}

Un tercer problema, que debe convertirse en el centro de la discusión pedagógica, lo encontramos en la ausencia de una relación directa entre educación jurídica y derechos humanos. Las propuestas metodológicas indican que "la idea de construcción de ciudadanía se apoya en el ejercicio de derechos, lo cual implica incorporar necesariamente una dimensión jurídica para la comprensión profunda de las diferentes posturas y sus consecuencias" (Seda, 2012, p. 25). La relevancia social de los contenidos y casos que se trabajan, el fortalecimiento de un espíritu crítico en los estudiantes, unido a una relación horizontal de construcción de nuevo conocimiento son exigencias que complementan dicha formación.

En América Latina y el Caribe, particularmente, se necesita una educación que contribuya eficazmente a la convivencia democrática, a la tolerancia y a promover un espíritu de solidaridad y de cooperación; que construya la identidad continental; que genere oportunidades para quienes hoy no las tienen y que contribuya, con la creación del conocimiento, a la trasformación social y productiva de nuestras sociedades" (Instituto de Educación Superior de la Unesco, 2008).

En la declaración mundial sobre educación superior se precisan temas de enorme importancia para la redefinición de la educación jurídica: 
Las instituciones de educación superior, a través de sus funciones principales (investigación, docencia y proyección social), dentro del marco de la autonomía institucional y la libertad académica deben propender hacia la interdisciplinariedad y promover el pensamiento crítico, así como una participación ciudadana activa que contribuya al desarrollo sostenible, la paz, el bienestar y el respeto de los derechos humanos, incluyendo la equidad de género (Unesco, 2009).

Entre los valores que se identifican como prioritarios en el nivel personal e institucional están aquellos que son condiciones básicas para ejercer la ciudadanía, como la autonomía progresiva, la confianza, la libertad, la capacidad de tomar decisiones e incidir en ellas y la responsabilidad, entre otros (Varela, 2012, p. 34). Hoy es imposible eludir la discusión pedagógica sobre valores, relaciones sociales y prácticas (Peces-Barba, 2007).

En los aprendizajes sobre derechos humanos, lo más importante es que los saberes y la práctica de los mismos se incorporen dentro de las aulas e instituciones educativas y en la comunidad en la cual se vive, con aplicación y ejercicio cotidiano de la tolerancia y el diálogo "con miras al desarrollo de un criterio propio, autónomo e informado"(Varela, 2012, p. 35).

Las evidencias que generalmente se presentan en relación con el debilitamiento de la cultura política en América Latina son comunes y llama la atención cómo hay prioridades a trabajar desde las facultades de derecho. Entre los aspectos más estudiados e identificados están la diminución en el interés por los asuntos públicos, la desconfianza y escepticismo de las políticas públicas y el rol del Estado, el debilitamiento de los vínculos políticos y sociales, el clientelismo, la corrupción y el deterioro del vínculo representativo.

Se trata de una ciudadanía de baja intensidad, en términos de O’Donnell (2003),y, frente a este grave diagnóstico, la educación tiene retos y prioridades importantes, entre los cuales es necesario incluir cambios curriculares en los que se "promueva el conocimiento de la realidad social y la construcción de criterios de actuación frente a ella" (Fortunato, 2012, p. 42).

Si tomamos como punto de partida la exigencia de pertinencia en las instituciones de educación superior y el trabajo que deben realizar para la solución de problemas (Brunner, 2000), son muchos y diversos los retos que afrontan. El profesor Orozco señala la importancia de una toma de posición desde las instituciones: "en esta dimensión es posible plantearse interrogantes 
de naturaleza ética y política y, desde aquellos, asumir como universidades un proyecto ético político y no solo técnico instrumental"(Orozco Silva, 2010).

En el mismo artículo se plantean tareas concretas para dar respuesta a esta exigencia, y se insiste en la importancia de asumir la responsabilidad social frente al fomento de la democracia y la necesidad de promover la participación de la sociedad civil como núcleo central en el fortalecimiento de la democracia. De igual forma existe la urgencia de revisar los esquemas de formación profesional y ética de los estudiantes en coincidencia con los trabajos señalados anteriormente y, además, la prioridad de desarrollar investigación que tenga en cuenta los problemas prioritarios de cada país y región, pues ellos son el punto de partida del impacto social y real de las instituciones educativas. Finalmente se estima muy importante examinar los avances que hacen las instituciones en materia de inclusión educativa. La combinación de todas estas exigencias evitará que se siga reproduciendo el modelo de "instituciones (educativas) exitosas en sociedades fracasadas” (Orozco Silva, 2010).

\section{A manera de conclusión}

En este aparte se describieron algunos de los problemas más graves de la educación jurídica en Iberoamérica, como la incidencia del formalismo jurídico en la formación dogmática de los abogados, los problemas metodológicos, la desconexión entre la teoría y la realidad social, entre otros. De igual forma, se reconocen las propuestas que se construyen para intentar superar o mitigar estos problemas con cambios en el enfoque propuesto sobre los procesos de enseñanza-aprendizaje, cambios en relación con los contenidos y cambios en las evaluaciones.

Se observan igualmente propuestas creativas para incursionar en el campo de la innovación pedagógica desde el derecho, dar un nuevo significado al concepto de competencias y orientarlo hacia una verdadera formación integral y humanística. La reflexión también debe darse en torno al concepto de extensión universitaria y aprendizaje-servicio, así como sobre la inclusión de los derechos humanos en los planes de formación de los estudiantes.

\section{B. El papel de las clínicas jurídicas en la transformación de la educación legal en Iberoamérica}

En esta sección se realizará un análisis basado en la presentación y documentación de algunos debates en torno a la educación legal clínica en la región. 
Se busca dar elementos que permitan entender las dificultades que ha tenido en Iberoamérica la incorporación de las clínicas como espacio de formación legal, en contraste con el formalismo jurídico que ha imperado. En primer lugar se examinarán los puntos de encuentro y diferencias entre las clínicas jurídicas y otros procesos de formación, como los consultorios jurídicos y los servicios legales universitarios. El tema siguiente será el de los modelos pedagógicos y la ubicación curricular de las clínicas, planteando la reflexión sobre los diversos modelos existentes y las opciones que en el marco de la autonomía universitaria pueden escoger las facultades de derecho de Iberoamérica.

A continuación se examinará un fenómeno muy interesante que se ha presentado en los últimos años en Iberoamérica: el de la evolución de clínicas jurídicas generales hacia clínicas jurídicas especializadas. Ilustraremos este fenómeno con algunos cuadros derivados de la investigación y con el análisis complementado por las voces de los docentes que entrevistamos en las diferentes clínicas de la región. El último tema que se examinará es el de los logros y dificultades de la educación legal clínica en Iberoamérica. Allí intentaremos sistematizar los puntos comunes y las diferencias manifestadas por los docentes y estudiantes de las clínicas en las entrevistas y encuestas, asî como en los encuentros realizados en las redes y las publicaciones que en el tema se han realizado en los últimos años. Se concluye con la demostración de los temas a mejorar y las fortalezas de la región, a partir de un proceso que implicó la visita directa y el escuchar a quienes son el corazón de la educación legal clínica en Iberoamérica.

Es indudable que las clínicas jurídicas han contribuido a un cambio en la forma de entender y enseñar el derecho, su principal aporte ha sido enfrentar a los estudiantes con su realidad y su entorno para incidir en cambios jurídicos y proyectar socialmente la profesión. Los estudiantes que participan en las clínicas desarrollan un espíritu crítico, ven la necesidad de incidir en la sociedad y contribuir a solucionar problemas (Torres, 2012).

\section{Clínicas jurídicas y Consultorios jurídicos. Una discusión conceptual o de fondo}

En la experiencia iberoamericana se identifica el que podríamos denominar en forma genérica servicio jurídico de acceso a la justicia, en ocasiones prestado directamente por abogados de oficio, voluntarios o pro bono en forma inde- 
pendiente, o a través de ONG, y asumido en forma complementaria, desde los años setenta, por las facultades de derecho de algunos países.

La figura adopta diversas denominaciones: servicio de asistencia jurídica gratuita (Venezuela, España, Chile, México), consultorio jurídico (Colombia, Perú), consultorio de asistencia legal (Panamá), servicio jurídico comunitario o clínicas de asistencia jurídica voluntaria, o clínicas de asistencia legal (Venezuela, Puerto Rico) (Boueiri, 2006).

La institución fue pionera en temas de servicio social de los programas de derecho, y su impacto en materia de atención a usuarios, convenios y trabajo comunitario es visible en muchos de los países latinoamericanos.

En relación con este tipo de servicios jurídicos, en el trabajo del profesor Carrillo (2011) se opta por la denominación genérica de clinicas, diferenciando entre las que llama clínicas de servicios jurídicos gratuitos (consultorios jurídicos) y las clínicas de interés público y derechos humanos.

En el modelo de los consultorios jurídicos o clínicas de servicios legales gratuitos e individuales la función según el profesor Carrillo:

Es atender las necesidades legales básicas de personas de escasos recursos económicos - los usuarios de la clínica- mediante los servicios o asesorías de estudiantes de derecho bajo la supervisión de abogados practicantes experimentados. Elénfasis de tales clínicas está, por un lado, en brindar un servicio social importante a la comunidad y, por otro, en ofrecer a los alumnos que participan en ella una experiencia práctica de abogacía durante su formación universitaria (Carrillo, 2011, p. 36).

En relación con el segundo modelo — clínicas de derechos humanossu objetivo es:

Llevar a cabo cualquier actividad en el marco del derecho internacional de los derechos humanos (DIDH) [...]. El hilo conductor que atraviesa dichas actividades es, siempre, la finalidad de ampliar el ámbito protector del derecho, así como impulsar la efectiva implementación y cumplimiento estatal, en el orden interno, de una normativa garantista acorde con el DIDH (2011, p. 37). 
El siguiente cuadro comparativo sintetiza las diferencias propuestas por el autor:

Tabla 1. Principales diferencias entre clínicas jurídicas tradicionales y clínicas de interés público

\begin{tabular}{|l|l|l|}
\hline Enfoque & Clínicas de asistencia legal gratuita & $\begin{array}{l}\text { Clínicas de interés público y derechos } \\
\text { humanos }\end{array}$ \\
\hline Número y tipo de \\
clientes & $\begin{array}{l}\text { Personas de escasos recursos con nece- } \\
\text { sidades de asistencia legal. }\end{array}$ & $\begin{array}{l}\text { Personas o grupos a quienes se les han } \\
\text { vulnerado sistemáticamente sus dere- } \\
\text { chos. No se mira el tema cuantitativo } \\
\text { derechos y la incidencia en políticas } \\
\text { públicas. }\end{array}$ \\
\hline Benefino el cualitativo.
\end{tabular}

Fuente: elaboración basada en Carrillo (2011,pp. 39-45).

En el caso colombiano, los consultorios jurídicos surgen en 1971 con el Decreto 196, en cuyo artículo 30 se establece la obligatoriedad de dicho servicio para los estudiantes de derecho y se señalan las competencias de los mismos. La reglamentación de los consultorios se da con el Decreto 765 de 1977, y ambas normas se complementan con el artículo $1^{\circ}$ de la Ley 583 de 2000. El siguiente cuadro muestra las exigencias mínimas para este servicio: 
Tabla 2. Consultorios jurídicos y clínicas jurídicas en Colombia

\begin{tabular}{|c|c|c|}
\hline & Regulación de los consultorios jurídicos & Las clínicas jurídicas \\
\hline $\begin{array}{l}\text { Aprobación } \\
\text { para iniciar } \\
\text { funcionamiento }\end{array}$ & $\begin{array}{l}\text { La normatividad exige que el consultorio } \\
\text { sea "aprobado por el Tribunal Superior del } \\
\text { Distrito Judicial donde funcione la respectiva } \\
\text { facultad"(Ley } 583 \text { de 2000). }\end{array}$ & $\begin{array}{l}\text { Han existido diversas opciones: } \\
\text { a) Aprobación como asignatura electiva por } \\
\text { la facultad. } \\
\text { b) Trabajo voluntario. } \\
\text { c) Línea de investigación para grado } \\
\text { aprobada por la facultad. } \\
\text { d) Inclusión como parte del consultorio } \\
\text { jurídico (área o estructura similar). }\end{array}$ \\
\hline $\begin{array}{l}\text { Tipología de } \\
\text { servicio de los } \\
\text { estudiantes }\end{array}$ & $\begin{array}{l}\text { Carácter obligatorio: "la prestación del servicio } \\
\text { del consultorio jurídico en ningún caso será } \\
\text { susceptible de omisión ni homologación" (Ley } \\
583 \text { de 2000). } \\
\text { Litigio en causa ajena como abogados de } \\
\text { pobres: "los estudiantes son abogados de } \\
\text { pobres y como tales deberán verificar la } \\
\text { capacidad económica de los usuarios"(Ley } 583 \\
\text { de 2000). }\end{array}$ & $\begin{array}{l}\text { Este ha sido uno de los obstáculos para la } \\
\text { creación de clínicas en Colombia. } \\
\text { En las existentes y adscritas al consultorio, se } \\
\text { llevan casos de la clínica y del consultorio para } \\
\text { no incumplir con este requisito. } \\
\text { Los casos de interés público no pasan por este } \\
\text { filtro económico, sino por un examen sobre su } \\
\text { viabilidad como litigio de alto impacto o de } \\
\text { interés social. } \\
\text { En las clínicas los estudiantes actúan } \\
\text { como abogados de interés público y } \\
\text { derechos humanos y cumplen con labores } \\
\text { de responsabilidad social universitaria, } \\
\text { aprendizaje-servicio y extensión. }\end{array}$ \\
\hline $\begin{array}{l}\text { Dirección del } \\
\text { servicio }\end{array}$ & $\begin{array}{l}\text { El director del consultorio debe ser un } \\
\text { "abogado titulado dedicado exclusivamente } \\
\text { al consultorio, con experiencia en docencia } \\
\text { universitaria o práctica profesional no inferior } \\
\text { a cinco (5) años". Debe "ejercer el profesorado } \\
\text { en la facultad o ser abogado de pobres del } \\
\text { Servicio Jurídico Popular" (Decreto } 765 \text { de } \\
\text { 1977). }\end{array}$ & $\begin{array}{l}\text { La dirección de la clínica la ejerce un abogado } \\
\text { titulado, docente universitario con dedicación } \\
\text { exclusiva o parcial en algunas universidades. }\end{array}$ \\
\hline $\begin{array}{l}\text { Dirección } \\
\text { administrativa }\end{array}$ & $\begin{array}{l}\text { Si se tienen más de } 100 \text { alumnos, deben contar } \\
\text { con esta dirección. }\end{array}$ & $\begin{array}{l}\text { No la tienen, salvo que compartan la que existe } \\
\text { en el consultorio jurídico. }\end{array}$ \\
\hline $\begin{array}{l}\text { Asesores en } \\
\text { derecho público, } \\
\text { penal, privado y } \\
\text { laboral }\end{array}$ & $\begin{array}{l}\text { Estas son las áreas que tradicionalmente tienen } \\
\text { los consultorios jurídicos colombianos, aunque } \\
\text { en algunos casos se han abierto nuevas áreas. } \\
\text { En relación con los asesores se sigue la } \\
\text { directriz que señala el Decreto } 765 \text { de } 1977, \\
\text { que exigía que fuesen "abogados titulados con } \\
\text { experiencia profesional no inferior a tres (3) } \\
\text { años". En dicha norma se exige tener un asesor } \\
\text { de tiempo completo por cada } 50 \text { estudiantes } \\
\text { o de tiempo parcial según los estudiantes que } \\
\text { coordine (nota: el Decreto } 765 \text { de } 1977 \text { ha sido } \\
\text { derogado por la Ley } 583 \text { de } 2000 \text { ). } \\
\end{array}$ & $\begin{array}{l}\text { Se denominan supervisores y cumplen la } \\
\text { labor de asesoría directa a los estudiantes } \\
\text { en los casos que asume la clínica. Según la } \\
\text { experiencia de las clínicas se observa que } \\
\text { son abogados titulados con experiencia en el } \\
\text { área de la clínica. Se recomienda al menos un } \\
\text { supervisor de tiempo completo por cada diez } \\
\text { estudiantes. }\end{array}$ \\
\hline Monitores & $\begin{array}{l}\text { Son egresados, o alumnos de último año de la } \\
\text { carrera. Se exige uno por cada } 20 \text { alumnos. }\end{array}$ & $\begin{array}{l}\text { En los casos en que la clínica está adscrita al } \\
\text { consultorio jurídico se cuenta con un monitor. }\end{array}$ \\
\hline $\begin{array}{l}\text { Condiciones } \\
\text { locativas y } \\
\text { logísticas } \\
\text { adecuadas }\end{array}$ & $\begin{array}{l}\text { La institución debe "disponer de locales en } \\
\text { condiciones adecuadas para el trabajo de los } \\
\text { profesores, monitores y alumnos, y muebles, } \\
\text { biblioteca y equipos suficientes para el } \\
\text { funcionamiento del consultorio". }\end{array}$ & $\begin{array}{l}\text { La clínica exige de unas condiciones locativas } \\
\text { adecuadas, sala de reunión para todo el grupo, } \\
\text { equipos y recursos para la labor que adelanta. }\end{array}$ \\
\hline
\end{tabular}




\begin{tabular}{|c|c|c|}
\hline & Regulación de los consultorios jurídicos & Las clínicas jurídicas \\
\hline $\begin{array}{l}\text { Dedicación de los } \\
\text { alumnos }\end{array}$ & $\begin{array}{l}\text { Por lo menos dos semestres en los dos últimos } \\
\text { años de la carrera. }\end{array}$ & $\begin{array}{l}\text { Por lo menos dos semestres en los dos últimos } \\
\text { años de la carrera. }\end{array}$ \\
\hline Competencias & $\begin{array}{l}\text { a) En los procesos penales de que conocen } \\
\text { los jueces municipales y los fiscales } \\
\text { delegados ante estos, así como las } \\
\text { autoridades de policía, en condición de } \\
\text { apoderados de los implicados. } \\
\text { b) En los procesos penales de competencia } \\
\text { de la jurisdicción ordinaria, como } \\
\text { representantes de la parte civil. } \\
\text { c) De oficio, en los procesos penales como } \\
\text { voceros o defensores en audiencia. } \\
\text { d) En los procesos laborales en que la cuantía } \\
\text { de la pretensión no exceda de } 20 \text { salarios } \\
\text { mínimos legales mensuales vigentes } \\
\text { y en las diligencias administrativas de } \\
\text { conciliación en materia laboral. } \\
\text { e) En los procesos civiles de que conocen los } \\
\text { jueces municipales en única instancia. } \\
\text { f) En los procesos de alimentos que se } \\
\text { adelanten ante los jueces de familia. } \\
\text { g) De oficio, en los procesos disciplinarios } \\
\text { de competencia de las personerías } \\
\text { municipales y la Procuraduría General de } \\
\text { la Nación. } \\
\text { De oficio, en los procesos de } \\
\text { responsabilidad fiscal de competencia de } \\
\text { las contralorías municipales, distritales, } \\
\text { departamentales y General de la } \\
\text { República. } \\
\text { De oficio, en los procesos administrativos } \\
\text { de carácter sancionatorio que adelanten } \\
\text { las autoridades administrativas, los } \\
\text { organismos de control y las entidades } \\
\text { constitucionales autónomas" (Ley } 583 \\
\text { de 2000). } \\
\text { La Corte Constitucional en Sentencia } \\
\text { C-143-01 del } 7 \text { de febrero de } 2001 \text {, } \\
\text { Magistrado Ponente doctor José } \\
\text { Gregorio Hernández Galindo, declaró } \\
\text { condicionalmente exequible este artículo y } \\
\text { señaló que en todos los casos la exigencia } \\
\text { debe ser que: "siempre que los estudiantes } \\
\text { que actúen en su desarrollo ejerzan el } \\
\text { derecho bajo la supervisión,la guía y el } \\
\text { control de las instituciones educativas a las } \\
\text { cuales pertenecen". }\end{array}$ & 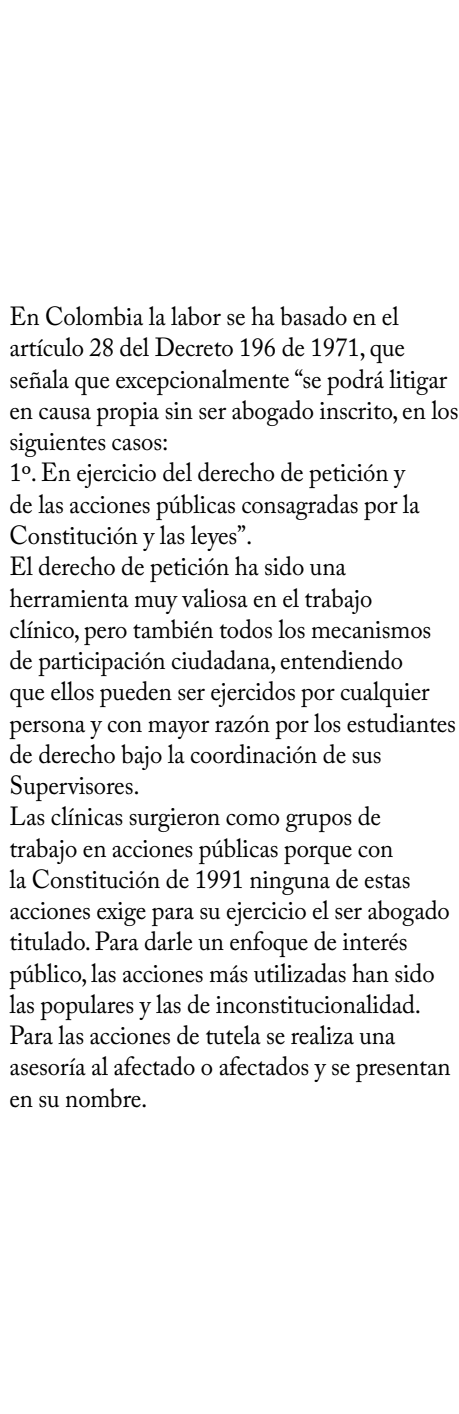 \\
\hline $\begin{array}{l}\text { Exigencia para } \\
\text { las actuaciones de } \\
\text { los estudiantes }\end{array}$ & $\begin{array}{l}\text { Autorización del consultorio jurídico para } \\
\text { realizar las respectivas actuaciones judiciales y } \\
\text { administrativas. }\end{array}$ & $\begin{array}{l}\text { Como regla general, en todas las actuaciones } \\
\text { judiciales se incluye la autorización del } \\
\text { consultorio jurídico y la mención de } \\
\text { pertenecer a la clínica jurídica. }\end{array}$ \\
\hline
\end{tabular}

Fuente: elaboración propia. 
En relación con esta regulación la Corte Constitucional colombiana se ha pronunciado en tres sentencias — su-044 de 1995, C-625 de 1996 y C-143 de 2001 - frente a los siguientes cuestionamientos:

- Garantía del debido proceso y el tema de la idoneidad de quienes actúan como defensores: $\mathrm{Al}$ respecto se señala:

Observa la Corte que la disposición últimamente transcrita, en cuanto establece que el defensor de oficio debe ser un abogado titulado, o un egresado de Facultad de Derecho oficialmente reconocida por el Estado, debidamente habilitado conforme a la ley o un estudiante miembro de consultorio jurídico, obedece a los lineamientos que la norma constitucional consagra sobre la asistencia del sindicado por un abogado dentro del proceso penal y, desde luego, en el policivo penal, el cual por su naturaleza jurídica similar, se rige por los mismos principios o garantías del debido proceso; pero se aclara, que aunque la norma permite confiar la defensa a quienes no son abogados titulados, ello no contraría el precepto del artículo 29 en referencia, pues debe entenderse que el legislador, facultado por la Constitución (art. 26) para determinar en qué casos se exigen títulos de idoneidad, ha habilitado especialmente al egresado de Facultad de Derecho que ha obtenido licencia temporal y al estudiante de derecho miembro de consultorio jurídico para actuar como defensores (Corte Constitucional, Sentencia su-044 de 1995, mp Antonio Barrera Carbonell).

- Discrecionalidad del legislador para establecer las excepciones:

De conformidad con lo previsto en el artículo 26 de la Constitución, es la ley la que puede exigir títulos de idoneidad para el ejercicio de las profesiones $y$, por lo tanto, mientras no contravenga preceptos constitucionales ni desconozca los elementos mínimos de los derechos fundamentales (como ocurre, según lo ha destacado la jurisprudencia, cuando se permite que cualquier persona sin aptitud ni preparación en el campo jurídico, asuma la defensa de un procesado), el legislador está autorizado para establecer los requisitos exigibles para el desempeño de las distintas actividades profesionales así como para 
estatuir grados o escalas de condiciones académicas según la naturaleza, contenido e importancia de los servicios que se presten en el ámbito de cada una de ellas.

Del mismo modo, será el propio legislador el que defina cuándo determinados rangos de la gestión profesional no hacen exigible un título, dando lugar a la validez de las actuaciones correspondientes si se cumplen otros requisitos que la misma legislación consagre (Corte Constitucional, Sala Plena, Sentencia C-626 del 21 de noviembre de 1996, mp José Gregorio Hernández Galindo).

- Garantía de los derechos y exigencia de supervisión y control por parte de las facultades:

La Sala concluye señalando que los numerales acusados del artículo $1^{\circ}$ de la Ley 583 de 2000, se ajustan a las disposiciones constitucionales y desarrollan principios constitucionales que garantizan derechos como el debido proceso, la solidaridad, el acceso a la administración de justicia, lo cual llevará a declarar la exequibilidad de las disposiciones demandadas [...]. Ordena: Declarar exequibles los apartes demandados de los numerales 2, 4, 5, 7,8 y 9 del artículo $1^{\circ}$ de la Ley 583 de 2000 , siempre que los estudiantes que actúen en su desarrollo ejerzan el derecho bajo la supervisión, la guía y el control de las instituciones educativas a las cuales pertenecen.

En la actualidad el debate de las universidades colombianas se centra en la necesidad de reglamentar o modificar la ley de consultorios jurídicos (Ley 583 de 2000). ${ }^{3}$

Si se opta por la reglamentación de la ley se estima importante tener en cuenta los siguientes aspectos:

- Reglamentar las circunstancias de pobreza, entendiendo que esta no solo hace referencia a falta de capacidad económica sino a situaciones

${ }^{3} \mathrm{Al}$ interior de la Red Colombiana de Clínicas Jurídicas y del Grupo de Acciones Públicos se han llevado a cabo discusiones importantes muchas de las cuales sintetizamos. 
de debilidad para la defensa del interés público o vulnerabilidad para el ejercicio de derechos o el acceso a la justicia.

- Señalar que las áreas establecidas normativamente son ejemplificativas y que en los consultorios jurídicos se puede abrir un área de interés público, desde la cual se puede coordinar el trabajo de las clínicas jurídicas.

- Se precisa incluir algún mecanismo idóneo que permita fortalecer los componentes de investigación y pedagogía formativa en los consultorios jurídicos y en las clínicas jurídicas.

- Debe buscarse la inclusión y la calidad en la atención a comunidades, grupos y colectivos como parte de la labor de las clínicas y consultorios jurídicos.

- Deben examinarse nuevas formas de intervención y legitimación por activa en los casos de consultorios y clínicas.

Si se opta por la modificación de la ley, figura con la cual estamos en mayor acuerdo, se recomendaría:

- Incluir las definiciones claras de consultorio jurídico y clínica jurídica como opciones para que se desarrollen en las universidades durante la etapa obligatoria de práctica jurídica en el marco del concepto de aprendizaje-servicio.

- Eliminar la categoría de abogado de pobres. Se estima que es un término peyorativo y discriminatorio. Podría incursionarse en el término de defensores de derechos humanos o defensores de interés público.

- Se podría trabajar con una categoría más abierta en materia de competencias, hablando no solo de personas individualmente consideradas, sino de comunidades y casos de interés público o colectivo. Debe irse más allá de la consideración socioeconómica de quienes solicitan los servicios de la clínica y eliminar la restricción en salarios mínimos para efectos de competencia, centrando la discusión en el tema de la vulnerabilidad en el acceso a los derechos individuales, de grupo o colectivos.

- Debe reconocerse, en el marco de la autonomía universitaria, la posibilidad de que las instituciones definan los objetivos misionales de este servicio que pueden orientarse a la enseñanza y pedagogía del 
derecho o a la garantía de acceso a la justicia a individuos y grupos vulnerables.

- El eje central de los consultorios jurídicos y clínicas debería ser la garantía del acceso a la justicia con un enfoque de derechos humanos y justicia social.

- Debe quedar claro que la forma de manejar los dos años de consultorio queda a discrecionalidad de las universidades en virtud de la autonomía universitaria, pero esos dos años deben ser necesariamente dedicados a labores de función social, y a generar procesos de formación profesional en prácticas y pasantías que se relacionen con el objetivo de aprendizaje-servicio.

\section{Los momentos históricos en que surgen y se desarrollan las clínicas jurídicas iberoamericanas. Historias paralelas}

Las formas de relacionamiento entre universidades y ONG en Iberoamérica posibilitan diversos modelos que inciden a su vez en la sostenibilidad de las experiencias clínicas:

a) Primacía de trabajos de universidades en alianza con ONG. Los estudiantes realizan las prácticas y tienen la asesoría docente en las ONG. Según Diego Morales, “se trata del 'modelo argentino'. Tiene gran apertura, es valioso para las organizaciones. Se garantiza el relevo generacional porque los mejores estudiantes luego ingresan a trabajar a la ONG" (Morales, 2012). La sostenibilidad de estas clínicas se garantiza por los convenios y por el permanente apoyo de las organizaciones con sus casos y requerimientos.

b) Modelo universitario de clinica, donde el liderazgo del trabajo lo asumen los programas de derecho en el nivel de pregrado o maestría y desde allí se manejan las relaciones con diversos actores sociales e institucionales para realizar su labor de impacto social. La sostenibilidad de estas clínicas se garantiza por la voluntad institucional de permanencia y trabajo con los estudiantes. Exigen la formación y permanencia de docentes calificados que asuman las labores de educación legal clínica.

c) En los últimos años han surgido también proyectos financiados para integrar alianzas interuniversitarias y crear o fortalecer clínicas jurí- 
dicas. Estos ejercicios se han realizado en Perú, en Argentina y en Colombia. La ventaja de estas propuestas radica en la posibilidad de optimizar recursos para la formación de docentes clínicos y en el intercambio que favorecen con experiencias más avanzadas y novedosas.

La siguiente figura nos muestra los periodos y etapas en el surgimiento de las clínicas en Iberoamérica.

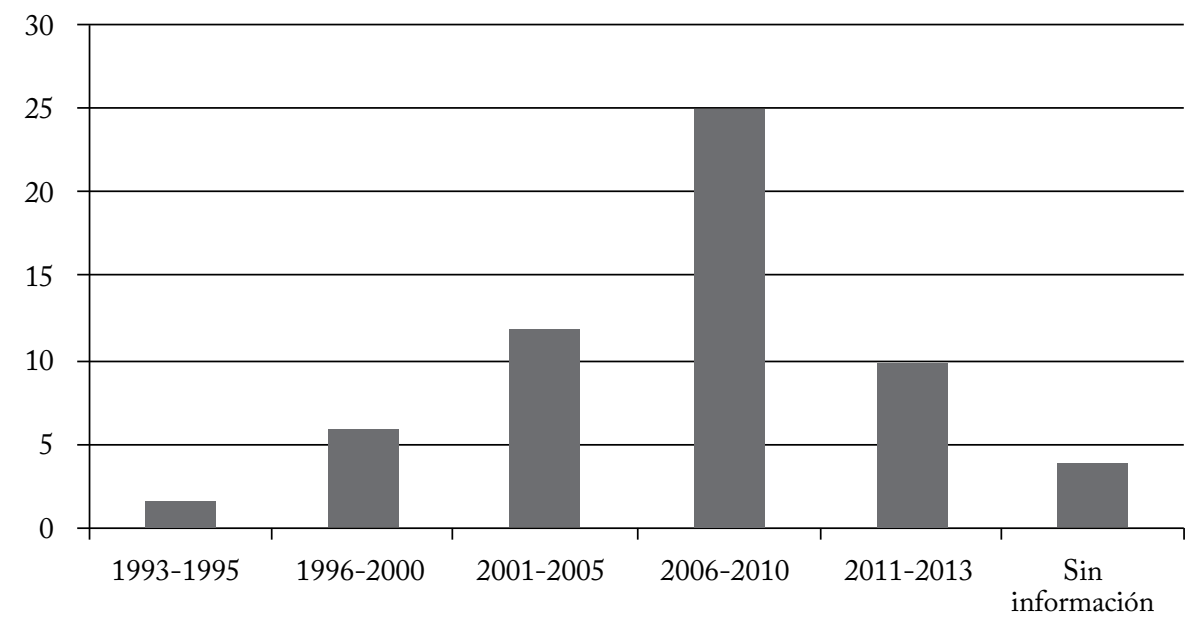

Figura 1. Surgimiento de clínicas jurídicas en Iberoamérica

Fuente: elaboración propia.

La primera generación de clínicas: los primeros intentos de formación en educación legal clínica en Latinoamérica, 1960-1980

En los trabajos de Gardner (1980), Rodríguez (2001), González (2004) y Bloch (2013) se hace la referencia expresa a la incidencia que tuvo el movimiento por el derecho y el desarrollo en los años sesenta. Estos intentos buscaron trasladar la metodología de la educación legal clínica a algunas universidades de Argentina, Colombia, Chile y Brasil, a través de recursos provenientes de la Fundación Ford y AId (Bloch, 2013, pp. 137-138). Universidades muy prestigiosas de Estados Unidos patrocinaron cursos de enseñanza clínica que tuvieron eco en algunas universidades que introdujeron el método de casos, entre las cuales se señala la Universidad de Los Andes, en Colombia. 
Se señalan también algunas experiencias de servicios sociales y jurídicos que surgen en este periodo en países como Venezuela (años sesenta). En dicho país se utiliza este término en la Universidad Central de Venezuela y luego en la Universidad Católica Andrés Bello, porque se establecieron centros jurídicos para la recepción, estudio y resolución de situaciones jurídicas reales, y, en 1985, se fundó en este país la Asociación Nacional de Clínicas y Asistencia Jurídica Voluntaria (Asocliva).

De igual forma, en el caso de Chile, la incidencia de este movimiento se dio en el mismo periodo (González Morales, 2004). Inicialmente se trabajó con apoyo de colegios de abogados con un bajo impacto, carencia de recursos y pocos docentes con conocimientos en el tema. Estos primeros intentos se acabaron con el golpe militar de Estado, pues se impuso la regresión a la cátedra magistral y a la escuela formalista del derecho (Castro-Buitrago, 2013, p. 145).

En el caso de Puerto Rico se señala que una de las pioneras en el continente fue la Universidad de Puerto Rico, a través de la clínica de asistencia legal de dicha institución, cuya existencia supera ya los 50 años y corresponde al impulso que en las universidades norteamericanas se dio hacia nuevos procesos de formación jurídica (Seijo-Ortiz, 2005).

En México las clínicas fundadoras fueron la del Instituto Tecnológico Autónomo de México (IтAм) y la del Centro de investigación y docencia económicas (CIDE), seguidas por la Iberoamericana.

Para definir cuál ha sido la clínica jurídica fundadora en Iberoamérica proponemos cuatro criterios: (i) su identificación desde los inicios como un trabajo de interés público y derechos humanos; (ii) su compromiso con el litigio estratégico; (iii) su impacto en las demás clínicas del continente y (iv) su trayectoria y sostenibilidad en el tiempo.

Según estos criterios, ubicamos la primera generación de clínicas jurídicas en el año 1993, en Argentina. Iniciamos este recorrido en el tiempo destacando que la primera clínica jurídica de Iberoamérica surgió en Argentina en 1993 con el convenio entre la Universidad de Buenos Aires (UBA) y el Centro de Estudios Legales y Sociales (cELs) e inició su funcionamiento en 1994. ${ }^{4}$ Son veinte años de trabajo ininterrumpido con grandes aprendizajes para el movimiento clínico iberoamericano.

\footnotetext{
${ }^{4} \mathrm{http}: / /$ www.cels.org.ar/servicios/?info=detalle Tpl\&ids=68\&lang=es\&ss=72
} 
La etapa inicial de cualquier clínica no es fácil, y una de las exigencias permanentes es la de adecuación del nuevo modelo. Así lo reconocen los profesores del ceLs:

\begin{abstract}
Se requería que la clínica articulara el trabajo concreto en litigio estratégico y la aplicación del derecho internacional. Para ello, era necesario lograr que todos los espacios de la clínica, incluso las clases teóricas, tuvieran un alto grado de integración entre sí y con la agenda de litigio del cels. La clínica atravesó, entonces, a dos años de su creación, su primera transformación significativa (cELs 2012,p.13).
\end{abstract}

Las transformaciones dan cuenta también de los momentos históricos que se viven y la agenda y prioridades que en derechos humanos les exigen nuevas respuestas. Una gran fortaleza de la clínica cELS-UBA es su capacidad de hacer litigio y también investigación de alto impacto, que generalmente se publican en los informes anuales de derechos humanos. Las líneas temáticas que manejan actualmente son cinco: "derechos económicos, sociales y culturales (DESC), salud mental, sistemas internacionales de protección, cárceles y violencia institucional" (Baladrón, 2013, p. 39).

Los nuevos tiempos exigen cambios; en los últimos cinco años han apoyado nuevas clínicas en Argentina, especialmente las de Jujuy y Neuquen "[...] hay nuevas clínicas con temas novedosos como salud mental, violencia contra las mujeres y tortura y cárceles entre otros; se puede tener incidencia en clínicas temáticas, pero hay una gran precariedad institucional. La crisis ha afectado en gran medida a las ong"(Morales, 2012).

De igual forma añade:

Se desdibujó el uso de clínicas para explicar simplemente herramientas o códigos procesales, que aunque se trabajan, la orientación es hacia los casos del litigio estratégico. Los temas procesales son herramientas de apoyo, no son herramientas de punta para provocar discusión. Se trabaja en diversas áreas para tratar de articular los temas de responsabilidad jurídica y la técnica procesal.

Concluye destacando que "la clínica es una de las caras más visibles del CELs" (Morales, 2012). 
En Venezuela se da para este mismo año el surgimiento de la clínica jurídica de la Universidad Andrés Bello, ${ }^{5}$ con un trabajo que tiene gran énfasis en atención de casos individuales y asesoría jurídica, pero que luego evoluciona especialmente en el tema de atención a migrantes.

En 1996 surge la Clínica de la Universidad de Palermo como un proceso de evolución desde una clínica de maestría a una clínica en el pregrado. En la maestría era una asignatura y allí se formaron muchos de los supervisores y profesores actuales de esta universidad (Nino, 2012).

En 1997 se crea una de las clínicas más emblemáticas del continente, la Clínica de Interés Público y Derechos Humanos de la Universidad Diego Portales. ${ }^{6}$ Felipe González, su fundador, cuenta cómo surge la idea de la clínica:

Había un grupo de profesores jóvenes; venían del mundo de derechos humanos y pensaron importante darle un giro al asunto. Varios habían estudiado en Estados Unidos, en particular yo había hecho un postgrado en American University; decidimos echar a andar esto [...] la creación de la clínica era un elemento importante para potenciar sin perder el horizonte teórico que ya existía.

La historia de las clínicas jurídicas en la Universidad Diego Portales se remonta a los años ochenta (dictadura), pero su impacto, solo fue medible diez años después, en los siguientes dos aspectos; por una parte en la operación del sistema judicial chileno (qué entendía el sistema judicial nacional lo que se estaba haciendo en las clínicas), y por otra parte una profunda reflexión sobre la enseñanza del Derecho, desde la academia, ya que muchas veces la docencia se basa en una jurisdicción vacía (2013).

En el año 1999 surgen dos clínicas de interés público, la Clínica de Derechos Humanos-Grupo de Acciones Públicas (GAP), en la Universidad del

\footnotetext{
${ }^{5}$ La información sobre la Clínica Jurídica de la Universidad Católica Andrés Bello en Venezuela se puede encontrar en: http://www.ucab.edu.ve/Clinica_Juridica.html

${ }^{6} \mathrm{http}: / /$ www.derechoshumanos.udp.cl/clinica/historia/
} 
Rosario, en Colombia, ${ }^{7}$ y la Clínica Jurídica de Acciones de Interés Público de la Universidad Católica del Perú. ${ }^{8}$

La Clínica Jurídica de la Universidad Católica se inicia con el liderazgo del profesor Gorki González M.y ha evolucionado hasta insertarse en el currículo de la Facultad de Derecho. Se describe como: "[...] un proyecto de la Facultad de Derecho destinado a brindar una mejor formación universitaria, buscando insertar a los alumnos en la concepción de responsabilidad social profesional a través de acciones de interés público en beneficio de grupos vulnerables que quizás no tendrían otro modo de ser defendidos". ${ }^{9}$

Por su parte, "la misión del GAP es promover la responsabilidad social universitaria mediante el uso de los mecanismos de protección de los derechos humanos y del interés público, generando a su vez espacios de asesoría jurídica para la comunidad y de investigación sobre temas públicamente relevantes". ${ }^{10}$ En esta clínica se trabaja en el ejercicio directo de acciones judiciales, mecanismos administrativos de defensa de derechos, acciones pedagógicas, incidencia en medios, trabajo pro bono, asesorías e investigación formativa, entre otras labores. Se ha priorizado la publicación de los casos emblemáticos, como una forma de divulgar el litigio estratégico y apoyar a las clínicas en formación.

Este primer momento tiene cuatro aspectos característicos: i) la educación legal clínica es liderada por un grupo de profesores al interior de las facultades de derecho o de las ONG en convenio con las universidades, que intentan romper con un modelo tradicional de formación y de asistencia jurídica; ii) La prioridad de las Clínicas es desarrollar y fortalecer el litigio estratégico; iii) El momento político en el cual surgen las clínicas (fin de las dictaduras en Argentina y Chile), evidencia la urgencia de trabajar por el fortalecimiento de la democracia y por la verdad, la justicia y la reparación para las vícti-

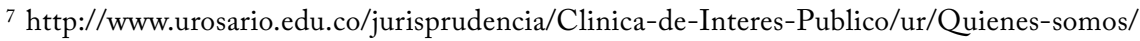
Que-es-el-Gap/

8 http://facultad.pucp.edu.pe/derecho/index.php?option=com_content\&task=view\&id=421\&Ite mid=112\#.UeOrto1M-So

${ }^{9} \mathrm{http}: / /$ facultad.pucp.edu.pe/derecho/index.php?option=com_content\&task=view\&id=419\&Ite mid=110\#.UUo0yBxhVJd

$10 \mathrm{http}: / /$ www.urosario.edu.co/jurisprudencia/Clinica-de-Interes-Publico/ur/Quienes-somos/ Mision/
} 
mas; iv) Para el fortalecimiento de las clínicas se constituye en este mismo periodo la Red Sudamericana (luego Latinoamericana) de clínicas jurídicas (Londoño, 2013).

Se destaca en el movimiento clínico de esta primera generación su liderazgo desde América Latina, la idea de constituir una red de apoyo y el impulso dado por los nuevos docentes en las universidades, además de un gran compromiso con la sociedad y con las nuevas exigencias que requería la educación jurídica.

En el caso colombiano la primera generación de clínicas se inaugura con el GAP y en este periodo se prioriza el ejercicio de litigio estratégico en defensa de derechos colectivos, a través de acciones populares (Ley 472 de 1998) y acciones de tutela. En el campo metodológico, estas clínicas plantean novedades en la forma de relacionamiento de profesores y estudiantes, en la construcción de aprendizajes derivados de la experiencia que se desarrolla en casos reales de litigio estratégico y, ante todo, este movimiento asume una posición crítica frente al formalismo imperante en la educación jurídica.

\section{La segunda generación de clínicas jurídicas en la región (2000-2010)}

La primera generación de clínicas se dedica a apoyar el surgimiento de nuevas propuestas en sus respectivos países, y luego en México, Brasil, Bolivia y Centroamérica.

La segunda generación de clínicas puede ubicarse en el decenio 20002010. Se trata de clínicas que nacen con toda la experiencia previa y los aprendizajes de un camino recorrido. Sus docentes son, en muchos casos, ex alumnos de las clínicas de primera generación y en el trabajo que realizan procuran mejorar y perfeccionar las experiencias que tuvieron.

En Chile se inicia este movimiento y se destacan el surgimiento de las clínicas de las universidades Alberto Hurtado (2001) y la Clínica Jurídica de la Universidad de Chile (2003). En 2004 nace un grupo significativo de clínicas:

En Argentina la Clinica de Migrantes, la cual constituye una verdadera novedad y muestra la evolución de la propuesta clínica. Su historia es muy particular, según lo relata su director:

En el 2004 el trabajo temático en materia de migrantes y refugiados y las fortalezas del cels hacen surgir la clínica. Hace 10 años surge 
esta clínica. En ese momento las ONG tenían una bandera: atacar la denominada Ley Videla que era totalmente violatoria de los derechos de los migrantes. Se organizó entonces un consorcio y una mesa por los derechos de las personas migrantes integrada por Caref, cels, sindicatos e investigadores. Se consideró importante apoyarse en la experiencia del cels-uba pues ya hacían litigio y tenían trabajo anterior en temas de repatriados (Asa, 2012).

Como puede observarse, esta clínica fue fruto de alianzas académicas y de ONG para trabajar un tema que inicialmente exigía cambios normativos y lobby legislativo, pero luego, al lograr la expedición de la Ley de Migraciones —Ley 25.871-, se vio la necesidad de continuar trabajando en orientación y trámite de casos y en apoyo para la expedición de una reglamentación, lo cual finalmente se produjo en el año 2010 (Reglamento Migratorio, Decreto 616/2010).

La Clínica Jurídica de la Escuela de Derecho de la Universidad Torcuato Di Tella en Argentina surge en alianza con la Acción por los Derechos Civiles (ADC) y este apoyo facilita el trabajo docente y el litigio estratégico (Gülco, 2012).

En Medellín (Colombia), surge la Clínica Jurídica de la Universidad de Medellín, pionera en el trabajo de educación legal clínica en la región y semillero de muchas de las nuevas clínicas de Antioquia. Su trabajo más destacado es en materia ambiental y en derechos humanos.

En el 2005 surge la Clínica Jurídica de la Universidad Nacional de Tucumán, que bajo el liderazgo de Mariela Puga fue una experiencia de enorme valor para toda América Latina, pero luego sufrió ataques desde la institucionalidad y la universidad a raíz del denominado caso "Rosarito", que develaba la ausencia de políticas públicas en materia de seguridad alimentaria para los niños y niñas en la provincia de Tucumán. La clínica desapareció y aunque traten de borrar su rastro, su memoria permanecerá en los nuevos ejercicios clínicos del continente.

En el mismo año, surgen las clínicas en España, con una característica interesante: en su gran mayoría, las primeras clínicas se forman en programas de máster (maestría) o en alianza de dichos programas con los de grado. La pionera fue la Clínica de Derecho Ambiental de la Universidad Rovira i Virgili, de Tarragona. En el 2006 aparecen las clínicas de la Universidad Carlos III: Clínica de Derecho Internacional de los Derechos Humanos, 
Clínica de Migrantes, Clínica de Igualdad y No Discriminación por Razón de Discapacidad y la Clínica de vin-sida. De igual forma surge la Clínica Jurídica por la Justicia Social de la Universidad de Valencia. En Colombia surge en este mismo año el Grupo de Derecho de Interés Público (G-DIP) de la Universidad de Los Andes.

También en 2005 surgen las clínicas en México, con la clínica del iт am y luego la Clínica de la Universidad Iberoamericana y la del cide. Dichas clínicas impulsaron trabajo clínico en derechos humanos, publicaciones muy reconocidas que aún se encuentran en la web, promovieron encuentros de clínicas en México y un encuentro de la Red Latinoamericana de Clínicas Jurídicas en el año 2007. Desafortunadamente las dos primeras clínicas ya no existen y aunque el cIDE continúa con trabajo clínico en pregrado, su enfoque está orientado a trabajo investigativo. El profesor Posadas describe así la situación actual: "A few but significant clinical legal education programs have been established in the last five years giving rise to an interesting, though still modest, new legal clinical wave. Bufetes jurídicos gratuitos (legal aid programs) play a role in these developments too" (Posadas, 2014).

El año 2007 trae también la formación de interesantes experiencias de educación legal clínica. En Chile nace la Clínica de Migrantes de la Universidad Diego Portales, la cual, según su directora, Helena Olea, logra "posicionarse como un referente en materia de atención clínica a inmigrantes, reconocimiento por otros actores, ONG y redes, investigación para generar los aportes documentados al Informe de Derechos Humanos en Chile y respaldo institucional" (Olea, 2013).

En España coincide con la formación de la Clínica Dret al Dret, de la Universidad de Barcelona (año 2009). Para su director y fundador:

La clínica es un proyecto institucional. Tiene que ver con el modelo de facultad que se quiere. Las clínicas son grupos de trabajo de estudiantes y profesores, donde se potencia la calidad de las prácticas, el servicio a la comunidad, la transferencia de conocimiento y la investigación. Esto las hace un proyecto de la facultad. La clínica ha de dar respuesta a necesidades actuales. No es una respuesta personal sino un modelo de facultad y de universidad (Madrid, 2013). 
Nace este año en Colombia, en la Universidad de Los Andes, la primera clínica en temas específicos de discapacidad, denominada Programa de Acción por la Igualdad y la Inclusión Social (PAIIs).

De igual forma surge en la misma universidad la clínica denominada: Justicia Global y Derechos Humanos. En esta clínica se trabajan temas de investigación y litigio estratégico en violencia, justicia y derechos humanos, economía global y derechos humanos y derecho global contra la discriminación. ${ }^{11}$

En el 2008 aparecen entre otras las siguientes clínicas: Clínica Jurídica de Acceso a la Información Pública, de la Universidad de Palermo, Argentina; Clínica Jurídica de Litigio Estructural, de la Universidad Nacional Mayor de San Marcos, Perú; el Grupo de Acciones Públicas del Icesi, en Cali, Colombia, y la Clínica de Interés Público de la Universidad Sergio Arboleda.

En México se intentó en el 2009 trasladar el modelo de alianzas onguniversidades a través de la ong Litiga, liderada por Graciela Rodríguez y Luis Miguel Cano y la Universidad Libre de México. Esta experiencia, desafortunadamente, solo duró un año. Las ong mexicanas han tenido que liderar solas el tema del litigio estratégico, como afirma Graciela Rodríguez: "el litigio de interés público se ha realizado por organizaciones de la sociedad civil [...], cada vez más las organizaciones incorporan un componente de litigio estratégico" (Rodríguez, 2013).

Los casos más sonados que en México llegan a conocimiento de la $\mathrm{Su}-$ prema Corte de Justicia de la Nación no vienen, en su mayoría, de clínicas, sino de organizaciones que se empiezan a dedicar a esto. No se constituyen como ONG de litigio estratégico; son organizaciones de derechos humanos a las que les incorporan un elemento de litigio. A veces no tienen la capacidad de llevarlo a cabo y contratan a otras organizaciones para realizarlo.

Esta segunda etapa de las clínicas, aunque prolífica, ha tenido experiencias fallidas, mayores dificultades y menor acogida por parte de las universidades para institucionalizar las nuevas propuestas, especialmente en el caso de México y Argentina. En los demás países continúa el liderazgo de los profesores, su contribución a través de planteamientos pedagógicos novedosos, como las clínicas especializadas y una participación más amplia en redes como la

${ }^{11} \mathrm{http} / / /$ derecho.uniandes.edu.co/index.php?option=com_content\&view=article\&id=53\&Itemid =260\&lang=es y http://justiciaglobal.info/ (fecha de consulta: $1^{\circ}$ de marzo de 2013). 
Global Alliance for Justice Education (GAJE) y la Red Latinoamericana de Clínicas Jurídicas).

\section{La tercera generación de clínicas (2010 hasta hoy)}

Las clínicas que incluimos en esta etapa son todavía clínicas en construcción, tienen mucho que aprender de sus antecesoras, pero también mucho que enseñar desde los debates internos que las han hecho surgir. La principal preocupación que nos planteamos es la de la sostenibilidad del trabajo de las clínicas: estos nuevos ejercicios deben nacer fuertes y con raíces claras en las universidades, para que no se conviertan en efímeros proyectos de uno o dos años, sino que tengan una trayectoria y un respaldo para la importante labor que realizan.

En el 2012 surge ClinHab, una clínica especializada en temas de vivienda, impulsada por las profesoras del área de Derecho Civil de la Universidad de Barcelona. Es un hito significativo en la historia de las clínicas por la novedad de su temática y la posibilidad de abordaje de problemas tan graves y de tan alto impacto social, como el de la burbuja inmobiliaria española (Colau, 2013).

La Clínica Jurídica en Derecho Inmobiliario y Mediación Residencial, en el marco del Proyecto Dret al Dret ("Derecho al Derecho") de la Universitat de Barcelona, ofrece, desde junio de 2012, un servicio gratuito de consultas sobre vivienda, conocido como ClinHab (www.clinicajuridicaimmobiliaria.org). Su objetivo es proporcionar respuestas a las preguntas formuladas por el público en general o canalizadas por entidades sociales y administraciones públicas, mediante el análisis de cada caso por parte de alumnos de los últimos cursos de derecho, que trabajan bajo la estrecha supervisión de expertos colaboradores y profesores de derecho privado. Desde su puesta en funcionamiento, ClinHab ha atendido más de 180 consultas, de las cuales aproximadamente el $40 \%$ han sido cuestiones hipotecarias y otro $40 \%$ arrendaticias; el restante $20 \%$ se refiere a otras cuestiones de derecho inmobiliario, como la vivienda social. Hemos llevado a cabo unas 30 reuniones semanales, donde se discuten los casos y las novedades legislativas y jurisprudenciales. Estos son algunos de los resultados de ClinHab. 
ClinHab es un servicio gratuito prestado por una Universidad pública, directamente accesible a las personas, por medio del cual se comparten los resultados de la investigación y de la docencia en un ámbito especialmente difícil para muchas personas en estos momentos, como es el de la vivienda (Viola de Mestre, 2013).

En el año 2013 se presenta una nueva etapa para las clínicas mexicanas y el profesor Posadas identifica siete clínicas:

I have identified seven Law School or University legal clinics in Mexico.Interestingly, the majority has been established very recently. Three of them were established with Usaid funds in order to work on the new adversarial criminal law system that is being gradually implemented in Mexico (American Bar Association Rule of Law Initiative (ABA ROLI) 2013]. These are the criminal procedural law clinics of $\mathrm{La}$ Salle University campus Cuernavaca, of the Autonomous University of Chihuahua Law School, and of the Escuela Libre de Derecho de Monterrey. All of them were established in 2013. Two other recent clinics have been established at UNAM. These are the Marisela Escobar Clinic of the Programa Universitario de Estudios de Género (Gender Studies University Program), ${ }^{12}$ and the Human Rights Clinic of the Programa Universitario de Derechos Humanos (Human Rights University Program). ${ }^{13}$ Both take students from UNAM Law School. ITAM has a new clinic that works in support of human traffic victims, nested within their Justice Access Center, which operates also as a bufete jurídico gratuito. ${ }^{14}$ Finally, the senior clinic in Mexico is the CIDE Law School Strategic Litigation Clinic. ${ }^{15}$

En este periodo nacen las clínicas de Derecho Penal Internacional y de Violencia Intrafamiliar y Género (vIG) en la Universidad del Rosario de

\footnotetext{
12 (Nota del texto original) http://www.pueg.unam.mx/index.php?option=com_content\&view=fro ntpage\&Itemid=92 (recuperado el 11 de octubre 2013).

13 (Nota del texto original) http://www.pudh.unam.mx (recuperado el 11 de octubre 2013).

${ }^{14}$ (Nota del texto original) http://caj.itam.mx/Paginas/index.html (recuperado el 11 de octubre 2013).

15 (Nota del texto original) www.cide.edu (recuperado el 11 de octubre 2013).
} 
Bogotá, en Colombia; la Clínica de Género y Violencia Intrafamiliar de la Universidad de Nariño, en Colombia; la Clínica de Género de la Universidad de Medellín y las nuevas clínicas jurídicas en México.

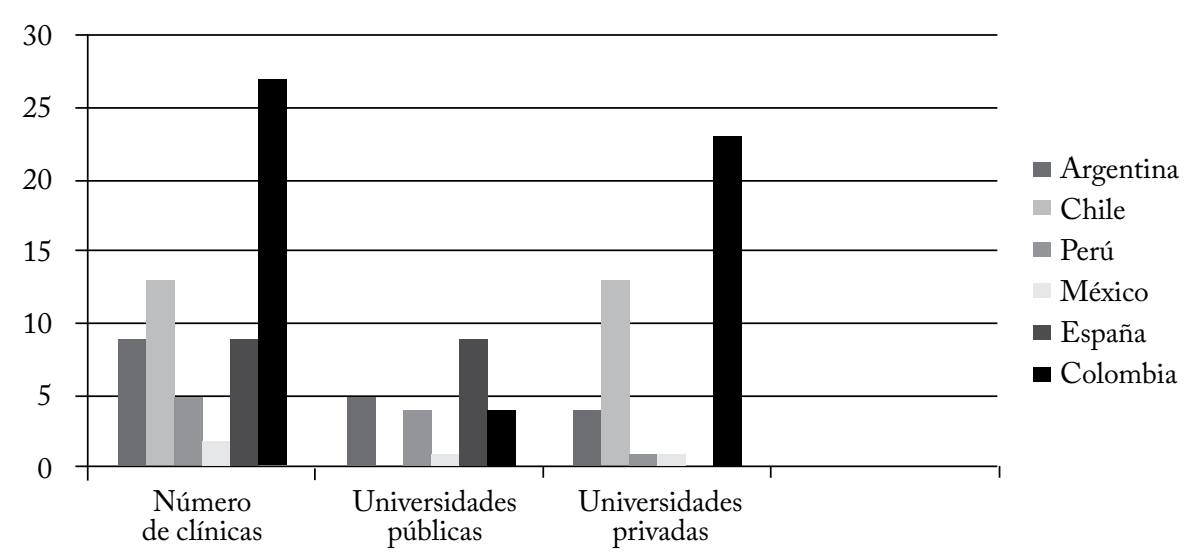

Figura 2. Clínicas jurídicas analizadas por países iberoamericanos en la investigación Fuente: elaboración propia.

En la revisión bibliográfica y directa que realizamos encontramos que a 2013, el país iberoamericano que tiene mayor número de clínicas jurídicas es Colombia, seguido por Argentina, Chile y España.

Para la selección de las clínicas se tuvieron en cuenta los siguientes criterios:

a) Participación de profesores y estudiantes en una labor que fortalece competencias de los estudiantes para su vida profesional.

b) Realización de trabajo pedagógico a partir de casos reales donde se interactúa para buscarles solución. Se consideran también como ejercicios clínicos los conceptos sobre casos reales, el lobby legislativo o ante entidades gubernamentales para la presentación de proyectos normativos en defensa de derechos humanos, la elaboración de informes sobre casos de vulneración de derechos humanos y la labor de street law.

c) Casos o ejercicios clínicos de impacto o emblemáticos finalizados. Se considera la posibilidad de que los casos tengan incidencia social, jurídica o política. 
Existe una cuarta característica que no aplicamos en esta ocasión porque es una de las mayores debilidades de las clínicas iberoamericanas: su visibilidad en medios de comunicación, redes sociales, internet y publicaciones.

Al examinar los avances en el trabajo de las Clínicas, proponemos clasificarlas en tres categorías para el análisis:

- Clinicas en formación: son propuestas clínicas muy recientes (inferiores a tres años) que se encuentran en proceso de reconocimiento académico institucional y que luchan por una sostenibilidad del proyecto. De igual forma incluimos en esta categoría a las clínicas que, a pesar de tener más tiempo, aun no reúnen con claridad los tres elementos propuestos.

- Clínicas consolidadas: son propuestas clínicas que reúnen las tres exigencias y ya tienen al menos un caso finalizado.

- Clínicas finalizadas: se trata de propuesta clínicas que no fueron sostenibles y se extinguieron por diversas razones institucionales, sociales o políticas.

Tabla 3. Muestra de clínicas examinadas en la investigación

\begin{tabular}{|l|c|c|c|c|}
\hline \multicolumn{1}{|c|}{ País } & $\begin{array}{c}\text { Número de clínicas } \\
\text { examinadas }\end{array}$ & Universidades & $\begin{array}{c}\text { Clínicas en } \\
\text { universidades } \\
\text { públicas }\end{array}$ & $\begin{array}{c}\text { Clínicas en } \\
\text { universidades } \\
\text { privadas }\end{array}$ \\
\hline Argentina & 9 & 7 & 5 & 4 \\
\hline Chile & 13 & 6 & 0 & 13 \\
\hline Perú & 5 & 5 & 4 & 1 \\
\hline España & 8 & 4 & 8 & 0 \\
\hline México & 7 & 6 & 2 & 5 \\
\hline Colombia & 27 & 21 & 4 & 23 \\
\hline Totales & 69 & 49 & 23 & 46 \\
\hline
\end{tabular}

Fuente: Elaboración propia.

En la revisión de las clínicas existentes, es preciso señalar que cuando se encontraron varias clínicas en una misma, todas fueron tenidas en cuenta. De esta forma la unidad de información de este trabajo son las clínicas iberoamericanas. El cuadro que veremos a continuación nos muestra un resumen de las cifras de clínicas examinadas y su distribución en Clínicas de Universidades Públicas o Privadas. 
La unidad de información que manejamos fueron las clínicas, pero también evidenciamos el número de universidades que las tienen:

El cuadro siguiente nos muestra las 69 clínicas que se examinaron en Argentina, Chile, México, Colombia, Perú y España. Luego haremos una profundización sobre el caso colombiano y las clínicas en este país.

Tabla 4. Muestra de clínicas jurídicas consolidadas y en formación en seis países de Iberoamérica

\begin{tabular}{|c|c|c|c|}
\hline País & Número de clínicas consolidadas & Clínicas en formación & $\begin{array}{l}\text { Clínicas que } \\
\text { desaparecieron }\end{array}$ \\
\hline Argentina & $\begin{array}{l}\text { Universidad de Buenos } \\
\text { Aires-cEls: } 1 . \\
\text { Universidad de Buenos Aires-CELs- } \\
\text { Caref: } 1 . \\
\text { Universidad de Palermo: } 2 \text {. } \\
\text { Universidad Nacional de Córdoba- } \\
\text { clip: } 1 . \\
\text { Universidad Torcuato di Tella: } 1 \text {. } \\
\text { Universidad Nacional del Litoral en } \\
\text { Santa Fe: } 1 . \\
\text { Universidad Nacional de La Plata: } \\
1 . \\
\text { Universidad de San Andrés: } 1 \text {. }\end{array}$ & $\begin{array}{l}\text { Universidad Siglo xxI- } \\
\text { Cedha: } 1 . \\
\text { Universidad Católica de } \\
\text { Córdoba-Cedha: } 1 .\end{array}$ & $\begin{array}{l}\text { Universidad de } \\
\text { Tucumán. } \\
\text { Universidad de } \\
\text { Comahue. }\end{array}$ \\
\hline Chile & $\begin{array}{l}\text { Universidad Diego Portales: } 6 . \\
\text { Universidad Católica de Temuco: } 2 . \\
\text { Universidad Central de Chile: } 2 . \\
\text { Universidad Alberto Hurtado: } 1 . \\
\text { Universidad Andrés Bello: } 1 . \\
\text { Universidad Adolfo Ibáñez: } 1 .\end{array}$ & & \\
\hline Perú & $\begin{array}{l}\text { Universidad Católica del Perú: } 1 . \\
\text { Universidad Nacional de San } \\
\text { Marcos: } 1 . \\
\text { Universidad Nacional de San } \\
\text { Agustín en Arequipa: } 1 . \\
\text { Universidad Nacional de San } \\
\text { Cristóbal de Huamanga en } \\
\text { Ayacucho: } 1 \text {. } \\
\text { Universidad Nacional del } \\
\text { Altiplano-Puno: } 1 .\end{array}$ & & \\
\hline España & $\begin{array}{l}\text { Universidad Carlos III } \\
\text { de Madrid: } 4 . \\
\text { Universidad de Valencia: } 1 . \\
\text { Universidad de Barcelona: } 2 \text {. } \\
\text { Universidad Rovira e Virgili de } \\
\text { Tarragona-Derecho Ambiental: } 1 .\end{array}$ & $\begin{array}{l}\text { Universidad Rovira e } \\
\text { Virgili de Tarragona- } \\
\text { Derechos humanos: } 1 .\end{array}$ & \\
\hline
\end{tabular}




\begin{tabular}{|c|c|c|c|}
\hline País & Número de clínicas consolidadas & Clínicas en formación & $\begin{array}{l}\text { Clínicas que } \\
\text { desaparecieron }\end{array}$ \\
\hline México & CIDE: 1. & $\begin{array}{l}\text { Universidad Autónoma de } \\
\text { México: } 2 \text {. } \\
\text { Universidad de la Salle } \\
\text { Campus Cuernavaca: } 1 . \\
\text { Escuela de Derecho Uni- } \\
\text { versidad Autónoma de } \\
\text { Chihuahua: } 1 . \\
\text { Escuela Libre de Derecho } \\
\text { de Monterrey: } 1 . \\
\text { ITAM-Clínica de Trata de } \\
\text { Personas: } 1 .\end{array}$ & $\begin{array}{l}\text { Escuela Libre de } \\
\text { Derecho. } \\
\text { Universidad } \\
\text { Iberoamericana. } \\
\text { ITAM-Clínica } \\
\text { Legal de interés } \\
\text { Público. }\end{array}$ \\
\hline Colombia & $\begin{array}{l}\text { Universidad Sergio Arboleda: } 1 . \\
\text { Universidad de Los Andes: } 3 . \\
\text { Universidad del Rosario: } 1 . \\
\text { Universidad Javeriana: } 1 . \\
\text { UPB: } 1 . \\
\text { Universidad de Antioquia: } 1 . \\
\text { Universidad de Medellín }: 1 . \\
\text { ICEsi: } 1 . \\
\text { Universidad del Norte: } 1 . \\
\text { Universidad Libre de Pereira: } 1 .\end{array}$ & $\begin{array}{l}\text { Universidad de } \\
\text { La Sabana: } 1 . \\
\text { Unaula: } 1 . \\
\text { Universidad Católica de } \\
\text { Oriente: } 1 . \\
\text { Universidad } \\
\text { del Rosario: } 3 . \\
\text { Corporación Universitaria } \\
\text { Remington: } 1 . \\
\text { Unisabaneta: } 1 . \\
\text { Luis Amigó: } 1 . \\
\text { Universidad } \\
\text { Surcolombiana: } 1 . \\
\text { Pontificia Universidad } \\
\text { Javeriana de Cali: } 1 . \\
\text { Universidad de Ibagué: } 1 . \\
\text { Universidad de Nariño:1. } \\
\text { Universidad } \\
\text { del Magdalena: } 1 . \\
\text { Corporación Universitaria } \\
\text { Autónoma del Caribe: } 1 . \\
\text { Universidad Cooperativa } \\
\text { de Colombia en Arauca: } 1 .\end{array}$ & $\begin{array}{l}\text { Universidad San } \\
\text { Buenaventura } \\
\text { (Medellín): } 1 .\end{array}$ \\
\hline
\end{tabular}

Fuente: elaboración propia. En el caso colombiano, el cuadro se basa en las encuestas que realizó el Ministerio del Interior a los decanos de las facultades de derecho de Colombia (2012).

\section{El estudio de caso de las clínicas jurídicas colombianas}

Uno de los hallazgos más interesantes en este trabajo se relaciona con la verificación de existencia de un numeroso grupo de clínicas en Colombia. En esta sección examinaremos los resultados de una investigación desarrollada por la Universidad del Rosario y la Dirección de Justicia Formal del Ministerio de Justicia (2013), que tomó como base la preocupación por la calidad del servicio en las prácticas jurídicas de las universidades colombianas y la 
necesidad de diseñar una propuesta de lineamientos de calidad para los programas de derecho.

En la encuesta del ministerio, se pretendía indagar sobre los consultorios jurídicos y las clínicas en los programas de derecho y profundizar sobre:

a) La estructura tecnológica de los procesos de atención jurídica.

b) La infraestructura de la planta física.

c) La Idoneidad del capital humano.

d) Los requisitos mínimos para la puesta en funcionamiento de un centro de atención jurídica.

e) Los tipos de servicios que prestan.

f) La diversidad de escenarios y campos de aprendizaje práctico.

La fuente de información fueron los documentos en los cuales 72 decanos de facultades de derecho del país daban respuesta a un cuestionario remitido por el Ministerio de Justicia colombiano en el año 2012. Dicha información se complementó con la consulta directa de las páginas web de las facultades y documentos de relatoría de los cuatro encuentros de la Red Colombiana de Clínicas Jurídicas.

A través del semillero de investigación y bajo la coordinación del Grupo de Derechos Humanos de la Universidad del Rosario, se realizó la sistematización y análisis de la información relacionada con la aproximación a un diagnóstico sobre las clínicas jurídicas en Colombia. Del informe final se destacan los siguientes aspectos (Londoño, 2013):

- En Colombia existen a 2013, según la información de los decanos, 28 clínicas jurídicas. Su distribución se concentra en las regiones Centro y Antioquia. En el resto del país son aún incipientes las experiencias, existen clínicas en formación y solo algunas consolidadas.

- Las clínicas en Colombia trabajan, en su gran mayoría, temáticas de interés público y derechos humanos. Han surgido también clínicas especializadas en temas como discapacidad, medio ambiente y derecho penitenciario, entre otros.

- La mayoría de las clínicas existentes tienen una relación directa o indirecta con el consultorio jurídico, ya que es en dicho espacio académico donde se ha logrado el apoyo de las facultades de derecho. 
Tabla 5. Existencia de clínicas jurídicas en Colombia a 2013

\begin{tabular}{|c|c|c|c|}
\hline Región & $\begin{array}{l}\text { Número de } \\
\text { clínicas }\end{array}$ & Universidades que tienen clínicas jurídicas & $\begin{array}{l}\text { Total de encuestas } \\
\text { respondidas por } \\
\text { región }\end{array}$ \\
\hline Centro & $\begin{array}{l}\text { Total: } 9 . \\
\text { Consolidadas: } 6 . \\
\text { En formación: } 3 .\end{array}$ & $\begin{array}{l}\text { Clínicas consolidadas: } \\
\text { Universidad Sergio Arboleda: } 1 . \\
\text { Universidad de Los Andes: } 3 . \\
\text { Universidad del Rosario: } 1 \text { GAP. } \\
\text { Pontificia Universidad Javeriana: } 1 \text {. } \\
\text { Clínicas en formación: } \\
\text { Universidad del Rosario: } 2 . \\
\text { Universidad de La Sabana: } 1 .\end{array}$ & 18 \\
\hline Antioquia & $\begin{array}{l}\text { Total: } 8 . \\
\text { Consolidadas: } 3 . \\
\text { En formación: } 5 .\end{array}$ & $\begin{array}{l}\text { Clinicas consolidadas: } \\
\text { Universidad de Antioquia: } 1 . \\
\text { Universidad de Medellín: } 1 . \\
\text { Universidad Pontificia Bolivariana: } 1 . \\
\text { Clinicas en formación: } \\
\text { Corporación Universitaria Remington: } 1 . \\
\text { Luis Amigó: } 1 . \\
\text { Unaula: } 1 . \\
\text { Universidad Católica de Oriente: } 1 . \\
\text { Unisabaneta: } 1 . \\
\text { Clínicas finalizadas } \\
\text { Universidad San Buenaventura: } 1 .\end{array}$ & 12 \\
\hline Suroccidente & Total: 5. & $\begin{array}{l}\text { Clínicas jurídicas consolidadas: } \\
\text { Icesi: } 1 . \\
\text { Clínicas jurídicas en formación: } \\
\text { Universidad de Ibagué: } 1 \text {. } \\
\text { Universidad de Nariño: } 1 \text {. } \\
\text { Universidad Surcolombiana: } 1 \text {. } \\
\text { Pontificia Universidad Javeriana: } 1 \text {. }\end{array}$ & 12 \\
\hline $\begin{array}{l}\text { Orinoquía y } \\
\text { Amazonía }\end{array}$ & Total: 1. & $\begin{array}{l}\text { Clínicas jurídicas en formación: } \\
\text { Universidad Cooperativa de Colombia en } \\
\text { Arauca. }\end{array}$ & 2 \\
\hline Costa Caribe & Total: 3. & $\begin{array}{l}\text { Clínicas jurídicas consolidadas: } \\
\text { Universidad del Norte: } 1 . \\
\text { Clínicas jurídicas en formación: } \\
\text { Corporación Universitaria Autónoma del } \\
\text { Caribe: } 1 \text {. } \\
\text { Universidad del Magdalena: } 1 \text {. }\end{array}$ & 9 \\
\hline Eje Cafetero & Total: 1. & $\begin{array}{l}\text { Clinicas jurídicas consolidadas: } \\
\text { Universidad Libre de Pereira: } 1 .\end{array}$ & 5 \\
\hline Santanderes & Total: 0. & & 14 \\
\hline Total & 27 & & 72 \\
\hline
\end{tabular}

Fuente: elaboración propia basada en las respuestas a la encuesta que realizó el Ministerio de Justicia en 2012 y complementadas por información en páginas web. 
- Aun es escaso el número de profesores que apoyan las clínicas existentes. No se han formado profesores en esta modalidad de educación legal, que es tan importante a nivel internacional.

- A pesar de que la primera experiencia de educación clínica tiene ya 14 años en Colombia, no existe un reconocimiento de esta figura en la mayoría de las facultades de derecho.

- En el análisis regional podemos observar un desarrollo desigual, pues mientras en las regiones Centro y Antioquia existen clínicas consolidadas y con gran apoyo institucional, las regiones de Costa Caribe, Eje Cafetero, Suroccidente y Orinoquía muestran avances interesantes con algunas clínicas en formación aunque son realmente pocos los resultados frente al número de facultades. Preocupa que en la región de los Santanderes no existe hasta la fecha ninguna clínica jurídica. Finalmente, es importante mencionar que en Colombia se constituyó desde 2011 la denominada Red Colombiana de Clínicas. Se han realizado cuatro encuentros de dicha Red e importantes esfuerzos en el fortalecimiento de la educación legal clínica. Es también reciente en Colombia la coordinación de acciones entre universidades y bufetes de abogados, a través del programa pro bono. Se destacan las experiencias de la Universidad del Rosario y la Universidad de Los Andes.

\section{Las clínicas de interés público y derechos humanos. Primer movimiento de clínicas jurídicas en Iberoamérica}

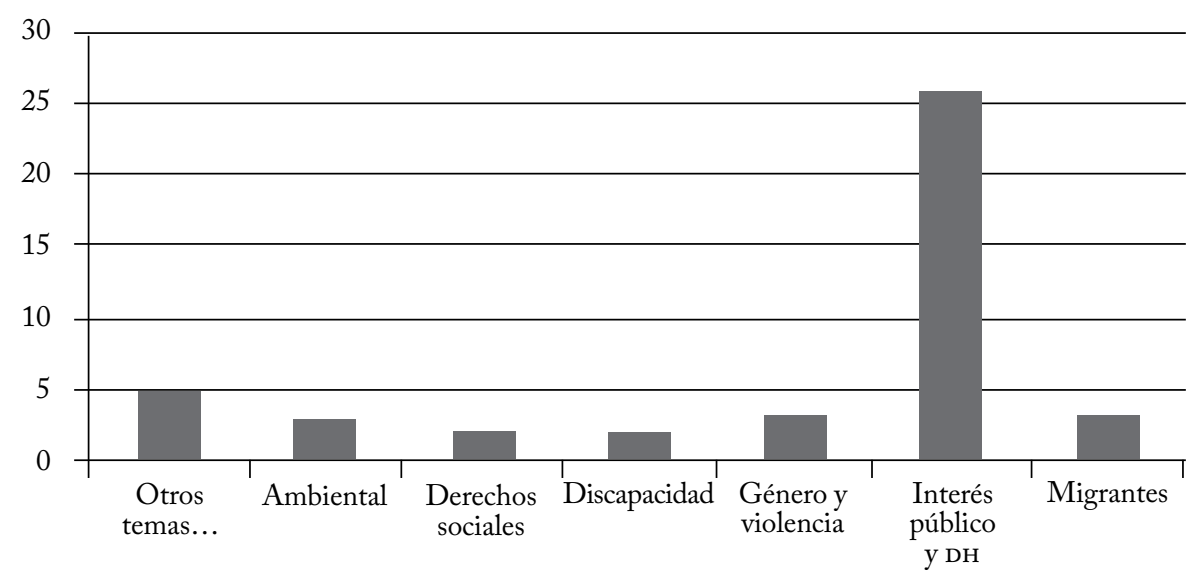

Figura 3. Temas prioritarios en la agenda de las clínicas de Iberoamérica 
Un concepto central para entender la educación legal clínica en Iberoamérica es el de derecho de interés público, eje que aglutina a la mayoría de las clínicas en lo que llamaríamos su primera fase de desarrollo (1992-2000). Los debates en todos los encuentros de clínicas y en la mayoría de los libros y revistas publicadas por la Universidad Diego Portales intentaron siempre dar una definición, buscando que el objetivo y nombre de las clínicas (clínicas de interés público) correspondieran a un campo de debate y entendimiento común para América Latina.

Para el profesor Courtis, en el denominado derecho de interés público se incluyen nuevas "estrategias y prácticas en el campo de la enseñanza y del ejercicio de la abogacía” y la reflexión sobre la "conceptualización y organización de prácticas materiales y discursivas en el ámbito jurídico”. Vale la pena señalar también que:

Los grupos que se identifican con la noción de derecho de interés público centran su interés en el desarrollo del propio derecho, poniendo énfasis en la necesidad de renovación de la enseñanza y de la práctica jurídica tradicionales. De allí que el tipo de estrategia elegida busque seleccionar casos de alto impacto público, incidir en el debate de ideas y en la formulación de propuestas de modificación normativa y curricular, sacar provecho del reconocimientos de nuevos derechos y de la consagración de instrumentos procesales novedosos, etc. [...] [incluye también] el interés público de consolidar y desarrollar el sistema de derechos y garantías y el sometimiento de los poderes estatales (y también de algunos poderes privados) a la Constitución y a la ley (Courtis, 2005, p. 168).

La gran dificultad surgió con la escuela tradicional del derecho público, donde se hacía equivalente el término interés público con el de interés estatal. El mayor debate del tema se dio en Argentina y allí, al igual que en varios países de Latinoamérica, se caracterizó esta nueva noción con varias propuestas que fueron siempre acompañadas por los nuevos docentes de universidades públicas y privadas que vieron en las clínicas una gran oportunidad de hacer real el concepto del interés público: 
- Reacción frente a las fallas en el acceso a la justicia y los graves problemas en la representación legal de ciertos sectores sociales. Se conceptualiza sobre acceso a la justicia para los grupos vulnerables, el acceso a la justicia en clave de igualdad material o sustantiva, la investigación empírica sobre necesidades jurídicas insatisfechas (Courtis, 2005, p. 164).

- A diferencia de las clínicas jurídicas norteamericanas, que se observan más centradas en el proceso pedagógico y educativo, en las clínicas latinoamericanas el enfoque apunta hacia el logro o contribución en la realización de cambios estructurales. Ven la educación legal clínica como una oportunidad de servicio a la sociedad con alto impacto.

- La crítica a la concentración de la enseñanza y del litigio en áreas tradicionales del derecho:

La instalación de la noción de derecho de interés público ha venido acompañada de un intento de rediscusión de las formas de enseñanza del derecho y de la articulación de la formación universitaria con la práctica profesional. Así se ha privilegiado la organización de cursos clínicos, la vinculación de las facultades de derecho con organizaciones de la sociedad civil y con instituciones de defensa de derechos humanos, el involucramiento de los estudiantes en la organización de actividades de debate público de temas jurídicos de interés público, su participación en la elaboración de documentos de toma de posición ante temas de trascendencia social, etc. (Courtis, 2005, p. 165).

- Diversificación temática; se propone la construcción de una nueva agenda de problemas a trabajar por las clínicas.

- El énfasis en el desarrollo del litigio sobre derechos constitucionales y derechos humanos. El concepto de interés público y el desarrollo de las clínicas en varios países latinoamericanos tiene que ver con la consolidación democrática y la existencia de nuevas cartas constitucionales (Colombia: 1991; Argentina: 1994; Perú: 1993). Coinciden con la masiva ratificación de tratados de derechos humanos y, en el caso Argentino: 
Con la incorporación de institutos procesales de garantía de derechos —como el amparo, el hábeas corpus y el hábeas data—a los nuevos textos constitucionales. En el plano institucional, se han multiplicado los esfuerzos por garantizar la independencia judicial, la del Ministerio Público y la de los órganos de contralor de la legalidad y la protección de los derechos humanos, como la Defensoría del Pueblo y la Auditoría General de la Nación (Courtis, 2005, p. 166).

- La práctica jurídica de las clínicas latinoamericanas se basa en el reclamo de derechos reconocidos por los textos constitucionales y las normas internacionales.

- La introducción de la temática de las acciones colectivas. Se ve como muy significativa la importancia que se le da en Latinoamérica a las dimensiones colectivas de la tutela de muchos derechos. Se han fortalecido debates académicos en materia sustantiva y en aspectos procesales, porque se cambian los paradigmas del derecho procesal tradicional. Se desarrolla ampliamente el amparo colectivo y en otros países las acciones populares.

Uno de los criterios elegidos por las clínicas jurídicas para seleccionar casos susceptibles de ser litigados judicialmente es el de la posibilidad de consolidar y ampliar la representación colectiva a través de miembros de la clase afectada u organizaciones de la sociedad civil que tengan como objeto la defensa de algún derecho específico [...]. Representantes de clínicas de interés público y de asociaciones vinculadas con la temática han apoyado también la introducción de modificaciones legislativas, tales como la reglamentación del amparo colectivo y de otras acciones colectivas, o la introducción de la figura del asistente oficioso o amicus curiae, cuando estos temas se han debatido en el ámbito de las respectivas comisiones parlamentarias (Courtis, 2005, p. 167).

En el caso colombiano, desde la Defensoría del Pueblo, con apoyo de las universidades y onG, se impulsó la regulación de acciones colectivas, populares y de grupo (Ley 472 de 1998). Durante estas dos décadas las acciones 
constitucionales han sido la principal herramienta de litigio estratégico en las clínicas colombianas.

\section{La práctica de las clínicas de interés público en diversos países iberoamericanos}

Las denominadas clínicas de interés público tienen dos elementos que les dan gran fortaleza: (i) la reflexión teórica sobre su objeto de trabajo y (ii) la relación directa con docentes de derecho constitucional y derecho público que deciden utilizar las acciones constitucionales como escenario para el litigio estratégico.

En Argentina se dieron varios cambios interesantes: (i) el agregado de un nuevo capítulo a la primera parte de la Constitución: se incluye una cláusula de defensa de la democracia y se consagran derechos políticos; (ii) la incorporación del bloque de constitucionalidad de los tratados de derechos humanos: jerarquía constitucional a 12 instrumentos internacionales y mecanismo de constitucionalización de otros tratados de derechos humanos.

"A la agenda sustantiva de los grupos que se identifican con la noción de derecho de interés público se ha agregado, entonces, una agenda procedimental, orientada a la discusión y mejora de los mecanismos procesales de defensa de los derechos privilegiados por su práctica" (Courtis, 2005, p. 175). Los debates más importantes se relacionan con temas de tiempos procesales prioritarios, legitimación, cuestiones de hecho y prueba, el efecto de las sentencias, amparos colectivos, requisitos de admisibilidad, eliminación de agotamiento previo de recursos administrativos como requisito para la interposición del amparo y acciones declarativas de inconstitucionalidad de carácter general (Buenos Aires).

Se destaca la consolidación institucional del tema a través de las universidades, las redes y las organizaciones.

Parte del impulso de la instalación de la noción de derecho de interés público está vinculada con instituciones universitarias. En este ámbito se ligan varias inquietudes teóricas y prácticas: la crítica a la enseñanza tradicional del derecho, un intento de renovación de la enseñanza jurídica que la reoriente hacia la práctica, la discusión sobre un espectro más amplio de perfiles posibles en el ejercicio de la profesión y la necesidad de vinculación de la universidad con la comunidad y con organizaciones de la sociedad civil [...]. 
La labor clínica fue acompañada por actividades de investigación académica sobre las herramientas del derecho de interés público y los avances en la materia (Courtis, 2005, pp. 180-182).

El caso argentino es especial: allí conviven y se relacionan las facultades de derecho y las ONG, existe un alto grado de pertenencia de los docentes a las ONG y esto facilita el litigio estratégico mediante alianzas.

\begin{abstract}
Así, y aprovechando la legitimación procesal de las organizaciones constituidas para la defensa de un derecho específico, las clínicas han servido en muchos casos como patrocinantes jurídicos de ONG en litigios de interés público — por ejemplo, en materia de derecho de los consumidores, derecho al medio ambiente, derecho a la salud, derechos de grupos discriminados, etcétera (Courtis, 2005, p. 182).
\end{abstract}

En estos 20 años, se han constituido nuevas organizaciones de la sociedad civil cuyo objeto es la defensa de causas de interés público, por ejemplo: la asociación por los derechos civiles (ADC), la Asociación Civil por la Igualdad y la Justicia (ACIJ) y Abogados y Abogadas del Noroeste Argentino en Derechos Humanos y Estudios Sociales (Andhes). Sus integrantes también son profesores en las universidades.

De la experiencia argentina se reconoce la importancia e impulso dado a buscar y consolidar nuevos actores del interés público. De igual forma el ejercicio ante el sistema interamericano de derechos humanos es sorprendente y visionario, solo posible por las alianzas de las universidades con las ONG. Finalmente destacamos cómo la agenda de interés público se ha fortalecido y repensado permanentemente.

Como retos específicos para Argentina, el profesor Courtis indica:

- "La consolidación de la perspectiva requeriría un salto cualitativo: pasar de un conjunto de experiencias piloto interesantes pero aisladas a su visualización como alternativa real a la formación jurídica y a la práctica profesional tradicionales" (Courtis., 2005, p. 186).

- "Para el afianzamiento de un espacio propio del derecho de interés público se necesitaría robustecer institucionalmente la vinculación 
de los distintos actores que participan del movimiento" (Courtis, 2005, p. 187). Propiciar mayores encuentros, debates y discusiones.

- "El trabajo en la perspectiva del derecho de interés público requiere, aún, de una mayor producción teórica que permita una definición conceptual más precisa de medios y fines, y la elaboración de materiales de enseñanza y divulgación, todavía escasos" (Courtis, 2005, p. 188). En todo caso se considera que esta labor promete mayores logros en el futuro.

\section{Características de las clínicas iberoamericanas}

En esta sección vamos a recoger los elementos comunes del trabajo en las clínicas iberoamericanas a manera de conclusión de la anterior sección y con el objeto de intentar dar respuesta a una pregunta específica: ¿qué diferencia a las clínicas iberoamericanas del modelo norteamericano?

Se encuentran tres elementos comunes y tres elementos diferenciadores: Elementos comunes:

a) Propuesta pedagógica que surge desde los profesores y se institucionaliza gradualmente. Esta es una característica necesaria para determinar la existencia de una clínica jurídica. Se debe evidenciar la participación de profesores y estudiantes en una labor que se orienta a fortalecer competencias profesionales, éticas, sociales y jurídicas de los estudiantes para su vida profesional.

b) Trabajo en casos reales. En las clínicas iberoamericanas existe trabajo pedagógico a partir de casos que surgen de muy diversas fuentes, pero que están anclados en la realidad que viven los países de la región. En el espacio de las clínicas se interactúa para buscarles solución.

c) De la revisión que se realizó se concluye que en esta categoría debemos incluir casos y ejercicios clínicos, entendiendo por tales otras formas de acercamiento y trabajo con la realidad, por ejemplo: conceptos sobre casos reales, el lobby legislativo o ante entidades gubernamentales para la presentación de proyectos normativos en defensa de derechos humanos, la elaboración de informes sobre casos de vulneración de derechos humanos y la labor de street law. 
d) Casos o ejercicios clínicos de impacto o emblemático finalizados. Se considera la posibilidad de que los casos tengan incidencia social, jurídica o política.

Elementos diferenciadores:

En esta sección miraremos dos aspectos que permean todos los anteriores y que si bien están implícitos en la educación legal clínica, en Iberoamérica muestran rasgos novedosos que hacen necesario dedicarles unas líneas:

\section{El rol de los estudiantes de las clínicas en Iberoamérica}

Poco se ha escrito sobre este tema y en muchas ocasiones se olvida el papel tan importante que cumplen los estudiantes en estos modelos.

Para intentar conocer el pensamiento de los estudiantes de las clínicas, se realizó una encuesta ${ }^{16}$ que nos permite examinar entre otros aspectos el valor que tiene la experiencia de educación legal clínica para los estudiantes, las fortalezas y debilidades de las clínicas desde su mirada y las recomendaciones más importantes.

La percepción de las clínicas es muy favorable, existiendo claridad y cumplimiento en la mayoría de sus elementos determinantes. Así mismo, existe un consenso general en relación con las actividades principalmente desarrolladas. Por último, también es posible extraer una valoración positiva del papel que cumple la clínica, entre los estudiantes que participaron o participaron en ella.

\begin{tabular}{|l|l|}
\multicolumn{2}{|c|}{ Encuesta a estudiantes que han pertenecido o pertenecen a clínicas jurídicas o clínicas de interés público } \\
\hline Marco de referencia & $\begin{array}{l}\text { Muestreo desarrollado a nivel regional (Colombia y países de Iberoamérica), partiendo } \\
\text { de la participación de estudiantes en eventos a nivel local y regional. }\end{array}$ \\
$\begin{array}{l}\text { Características de los } \\
\text { encuestados }\end{array}$ & $\begin{array}{l}\text { Estudiantes del programa de derecho que hayan participado o participen formalmente } \\
\text { en el desarrollo y funcionamiento de clínicas legales al interior de instituciones de edu- } \\
\text { cación profesional formalmente reconocidas. }\end{array}$ \\
Muestreo & $\begin{array}{l}\text { Encuesta desarrollada de modo virtual a través del sistema Survey Monkey, implemen- } \\
\text { tándose tres compiladores: link directo a formulario, invitación específica a encuestado } \\
\text { e invitación a participar a través de redes sociales (Facebook). }\end{array}$ \\
\hline Fropiedades & $\begin{array}{l}\text { Fueron resueltos 61 formularios, entre los tres compiladores activos: link (13), invitación } \\
\text { (44/85), redes (4). }\end{array}$ \\
Autores & Entre marzo 28 y mayo 28 de 2013. \\
\hline $\begin{array}{l}\text { Grupo de Investigación en Derechos Humanos - Línea de Investigación en Educación } \\
\text { Legal Clínica- de la Universidad del Rosario (Bogotá, Colombia). }\end{array}$
\end{tabular}


La clínica como experiencia pedagógica y su impacto en el futuro profesional: según la encuesta, el $65 \%$ de los estudiantes consideró que su tránsito por la clínica fue una buena experiencia, con aspectos novedosos y diferentes a las demás asignaturas. Adicionalmente, el 26,7\% consideró que su experiencia en la clínica fue determinante a la hora de decidir su futuro laboral, lo que corrobora el impacto positivo de las clínicas en los estudiantes que participan en ellas.

Actividades clínicas más valoradas por los estudiantes: los estudiantes consideran que la atención a casos de alto impacto o litigio estratégico es la principal actividad que desarrollan las clínicas (80,3\%). Destacan también las tareas de investigación (77\%) y la participación en charlas o conferencias $(75,4 \%)$. Por último, también contemplaron la atención a casos individuales, con el 62,3\%.

Elementos de la educación legal clinica: las respuestas a este ítem nos permitieron constatar el cumplimiento de las exigencias de educación legal clínica en las universidades iberoamericanas. Los estudiantes señalaron que en sus clínicas se trabajaron casos reales en los que se buscaba una solución y casos de impacto o emblemáticos (100\%). Luego destacaron la participación de estudiantes y profesores con el 96,7\% y la pertenencia a redes con el 88,5\%.

Desarrollo de competencias en la educación legal clínica: los estudiantes demostraron un gran interés por la responsabilidad social, con una valoración media de 4,56 sobre 5 . Muy de cerca, ubicaron la comprensión de problemas $(4,49)$ y la capacidad para la investigación $(4,43)$.

Con la educación legal clínica, una de las competencias que más se fortalecen es la investigación. Sobre ella, los estudiantes afirman: “[...] un aspecto fundamental para las clínicas, si pretenden tener un enfoque investigativo, es que los estudiantes al final de su paso por la clínicas tengan muy claro la metodología de la investigación desde un enfoque cuantitativo, cualitativo y mixto. En especial sobre el proceso de investigación en cada enfoque (planteamiento del problema, formulación de la hipótesis, diseño de la investigación, recolección y análisis de datos, etc.)”.

Exigencias para el trabajo en las clínicas: los estudiantes identificaron las características que consideran pertinentes para participar en las clínicas y sus principales exigencias son: (i) compromiso frente al grupo y a las labores asignadas, con una media de 4,82, (ii) el gusto o afinidad con las temáticas tratadas $(4,61)$, y (iii) la capacidad de trabajo en grupo $(4,56)$. 
Los estudiantes reconocen su papel en el impulso y renovación de la educación legal clínica y afirman que "[...] es fundamental que el estudiante perteneciente a la clínica esté entregado a la labor social, y empeño de investigar y ayudar a solucionar las problemáticas surgidas".

En la sección de recomendaciones, los estudiantes priorizan el tema de la selección de participantes, además de su responsabilidad social y compromiso.

Exigencias para los docentes clinicos: al referirse al rol de sus profesores, destacaron tres aspectos: (i) el compromiso frente al trabajo y frente a sus estudiantes, con una media de 4,89 puntos; (ii) facilidad para el trabajo en grupo y seguimiento de metodologías claras $(4,77)$ y (iii) experiencia académica $(4,53)$.

El papel de los docentes clínicos está relacionado directamente con el fortalecimiento de valores sociales y éticos frente a su profesión y reconocen que ellos son los llamados a "incentivarlos a investigar para fortalecer su conocimiento".

Al igual que en el tema de los alumnos, los estudiantes consideran que el proceso de selección de los docentes clínicos debe ser riguroso; esto asegura la calidad. "Los profesores deben tener experiencia en el área de litigios para guiar mejor la parte de litigio estratégico" y disponibilidad de tiempo para "que el estudiante tenga mayor acompañamiento profesional y educativo en todo momento".

Temáticas para la educación clínica: los estudiantes se refirieron a las áreas que consideraron como más importantes, para ser objeto de trabajo clínico. Sobresalen en su elección los temas de (i) derechos sociales, pobreza y exclusión, con una media de 4,58; (ii) temas de género y violencia contra las mujeres $(4,46)$ y (iii) el medio ambiente $(4,42)$.

Consideran necesario "[...] que la labor social se refleje en la formación de los nuevos abogados", además de "articular los trabajos en las clínicas en torno a las principales problemáticas del país” y hacer una reflexión profunda sobre el significado del "litigio de alto impacto y la forma de realizarlo".

Naturaleza de las clínicas: en este aspecto, los estudiantes prefieren la opción de prácticas voluntarias (52,5\%), seguida por la opción de asignatura electiva dentro del pregrado (23\%) y también algunos consideraron la opción de convertir la clínica en una asignatura obligatoria $(13,1 \%)$.

Recomendaciones en relación con el trabajo interinstitucional de las clinicas: los estudiantes conocen y valoran el trabajo en redes y consideran que: "una buena forma de mejorar la educación legal clínica sería creando canales in- 
terinstitucionales para dar mayor fuerza a las acciones como parte de una comunidad y de un grupo específico". De igual forma, estiman que debe fortalecerse el trabajo pro bono.

Para el trabajo de las clínicas, se consideran muy valiosos los ejercicios que permiten "Entablar conexiones permanentes con fundaciones, oNG, y algunas entidades estatales como la Defensoría del Pueblo".

Ajustes curriculares: para los estudiantes colombianos, "la clínica jurídica se podría realizar al tiempo con el consultorio jurídico, así existiría una mayor coordinación entre las prácticas".

En relación con la valoración de las clínicas, los estudiantes consideran que es necesario "que tenga valoración cuantitativa y créditos. Que se pueda hacer por más de un año". También consideran que esta experiencia debería ser abierta y electiva para todos los estudiantes de las facultades de derecho. Finalmente, los estudiantes reclaman "mayor voluntad política de las directivas de universidades, mayor interacción de las áreas, mayor difusión, mayor constancia”.

\section{Incidencia social de las clínicas}

Retomando el tema de los elementos diferenciadores de las clínicas en Iberoamérica, es preciso señalar su incidencia social, política y jurídica, como una de las mayores fortalezas.

Las clínicas PIHR se conciben a sí mismas no solo como una herramienta pedagógica para la enseñanza del derecho, sino también como agentes de cambio democrático en casos de debilidad institucional o insuficiencia de los Estados. Se caracterizan por su actuación en defensa de minorías (grupos o individuos) con desventajas sociales, políticas o culturales (Carrillo, 2011,p. 90).

Para Carrillo y Espejo existen dos características que distinguen a las clínicas latinoamericanas de sus "padres fundadores", las clínicas anglosajonas:

(i) En ellas tiene un lugar preponderante la defensa de imperativos de justicia social, incorporando a diversos actores sociales de sus democracias constitucionales; (ii) el litigio en estas clínicas ha revigorizado la adopción e implementación del derecho internacional de 
los derechos humanos, por sus estrategias creativas orientadas hacia los derechos económicos, sociales y culturales (2011, p. 91).

Una pregunta muy interesante que se ha planteado al interior de la Red Colombiana de Clínicas Jurídicas se refiere a cómo resolver la tensión entre los propósitos de formación y los de impacto social del trabajo clínico. Al respecto señala Fajardo (2012) que: "no hay riña entre el impacto y el aprendizaje. En Colombia solo se mide el impacto. Nos faltan sistemas de medición del aprendizaje".

En relación con el compromiso ético de las clínicas, la orientación de una gran mayoría de ellas en América Latina es hacia el interés público, los derechos humanos y el apoyo a comunidades en situación de vulnerabilidad. Es necesario complementar esta labor con la misión pedagógica de la universidad: la formación de los estudiantes.

Complementando este tema, Hurtado (2013), considera que las clínicas son una propuesta que acerca a la realidad. A través de este trabajo se busca repensar la realidad social, e involucrar a los estudiantes en ella. En las clínicas se combina lo teórico y lo práctico, lo ético y lo jurídico, lo individual y lo colectivo. No se trata de una práctica jurídica asistencialista, pues en la clínica se realiza acompañamiento directo, visibilización de las necesidades y búsqueda de transformaciones sociales sin sustituir al Estado.

\section{Los modelos pedagógicos y la ubicación curricular de las clínicas}

\section{¿Las clínicas jurídicas son un nuevo modelo pedagógico?}

En la educación legal clínica existen lineamientos claros de un modelo pedagógico en construcción donde se cumplen características de la nueva pedagogía (Unesco,2013), como la exigencia de ser procesos centrados en los estudiantes, la integralidad y manejo sistémico de los resultados y contenidos del aprendizaje, habilidades y competencias y la relación directa de este modelo como respuesta a necesidades sociales de acceso a la justicia para los grupos más vulnerables, además de la promoción de la participación social y el fortalecimiento de la democracia. 


\section{¿Qué concepto de modelo pedagógico tomamos como punto de partida?}

Esta es la pregunta central, porque solo en el acercamiento a las nuevas corrientes pedagógicas podemos entender la dimensión del problema que se aborda y buscar respuesta a la inquietud inicial.

Un modelo es una herramienta conceptual desarrollada para entender mejor algo, es la representación del conjunto de relaciones que describen un fenómeno. Un modelo pedagógico es una representación de las relaciones que predominan en la experiencia de enseñar y representa la teoría pedagógica predominante en este proceso, tal como lo manifiesta Flores [...], hace referencia a la interrelación entre los eventos externos de organización de la información y los procesos cognitivos internos (Murcia, 2014).

Para los expertos, un modelo pedagógico debe dar respuesta al menos a cinco exigencias claras:

"1. Las metas o propósitos de formación, que en este caso supera el concepto de adquisición de conducta, para llegar al desarrollo de competencias.

2. El concepto de desarrollo humano donde el aprendizaje puede ser concebido como un proceso genético espontáneo, natural, interior y autodirigido, o como un proceso de aprendizaje inducido desde afuera.

3. Los contenidos y su secuencia que identifica qué enseñar y depende de la naturaleza de la ciencia.

4. La relación entre los actores: profesor-estudiante que puede ser concebida como aquella que está centrada en el profesor hasta considerarla como una relación de construcción colectiva de conocimiento, donde de manera horizontal se respetan los saberes individuales. Los cambios en esta relación dependen de la forma como se consideren los roles de los actores participantes en el proceso. 
5. El parámetro técnico-pedagógico o modelo didáctico que incluye los métodos ${ }^{17}$ y técnicas de enseñanza-aprendizaje, ${ }^{18}$ los recursos o ayudas didácticas y la forma como se hace la evaluación; ¿cómo logramos que se dé un aprendizaje? La respuesta varía si la enseñanza está centrada en los contenidos o en el estudiante (Murcia 2014).

En relación con el tema de las evaluaciones, las clínicas iberoamericanas aún no han incursionado para hacer una reflexión en profundidad. Existen criterios para la evaluación, como la participación, la asistencia a las sesiones programadas, la calidad del trabajo y el cumplimiento de los términos de las acciones.

En las clínicas jurídicas norteamericanas, se ha avanzado más en el tema y, por ejemplo, en la Universidad de Minessota, se utiliza para la evaluación de los estudiantes una propuesta de seis categorías de competencias clínicas, pensando en lo que es la formación de un abogado en el área de la clínica. En esta propuesta se tienen en cuenta: (i) el conocimiento de la teoría, normatividad y jurisprudencia; (ii) razonamiento y argumentación; (iii) investigación e innovación en sus propuestas (espíritu crítico); (iv) principios éticos; (v) relaciones con usuarios y clientes, y (vi) habilidades orales y escritas. La calificación se da según el avance de cada estudiante.

La profesora Di Matteo (2012) define la evaluación educativa como "aquella que apunta a la innovación y a la mejora y no a la comprobación; recupera la subjetividad y tiene como garantía el diálogo, la posibilidad de crítica y la circulación. Es una evaluación situada”, donde los criterios deben ser explícitos (p. 78). Todos son elementos que al interior de las clínicas deben reflexionarse y explicitarse para avanzar en términos de calidad y responsabilidad del trabajo.

\section{¿La educación legal clínica es un método o un modelo?}

En la educación legal clínica los debates giran en torno a si se trata de un verdadero modelo pedagógico o si simplemente es un método o una didáctica.

\footnotetext{
17 (Nota del texto original) Método es la "herramienta con la que el objeto de estudio es trabajado por parte del aprendiz para que adquiera reconocimiento"(Secol, 2007).

${ }^{18}$ (Nota del texto original) Considerados como procesos integrales del individuo que involucran no solo el ámbito cognitivo, sino el afectivo, social, psicomotor y de valores.
} 


\begin{abstract}
Así, se ha entendido en Colombia que las clínicas son una estrategia innovadora para la enseñanza práctica del derecho (Vásquez-Santamaría, 2008). Dentro de esos aspectos innovadores se incluyen la relación práctica-teoría, compromiso social, interdisciplinariedad, litigio estratégico, interés público, población vulnerable, acciones constitucionales, entre otros. Y metodológicamente podría afirmarse que la EACD se soporta en la conjunción de las bondades de los presupuestos de los modelos autoestructuralistas, heteroestructuralistas y la andragogía (Reacd, citado en Torres Villarreal, 2014).
\end{abstract}

Si examinamos los aportes de las clínicas y su relación con la implementación de un modelo pedagógico, encontramos que los aspectos más significativos son: (i) aprendizaje activo, (ii) formación integral, (iii) aprendizaje constructivo, (iv) aprendizaje autorregulado, (v) aprendizaje significativo y (vi) aprendizaje-servicio.

La formación integral es entendida como aquella que permite y fomenta el desarrollo de las dimensiones espiritual, intelectual, cultural, psicosocial y física del ser humano. En la aplicación de este concepto a la educación legal clínica, encontramos que en estos procesos se promueve el acercamiento, análisis y comprensión de las realidades sociales, políticas, culturales, ambientales y económicas de la sociedad. De igual forma se refuerza el pluralismo, la autonomía, el respeto, la honestidad y la responsabilidad personal y profesional.

En el aprendizaje activo los estudiantes son protagonistas de sus propios procesos de aprendizaje. En la educación legal clínica se utilizan las entrevistas, simulaciones, juegos de roles, discusiones y el análisis de casos que implican reflexión profunda y aportes creativos. De igual forma se facilita el aprendizaje colaborativo a través de la interacción de los estudiantes. Con estas estrategias se potencia el aprendizaje y nuevas habilidades en los estudiantes.

El aprendizaje de la educación legal clínica es además constructivo y está enmarcado en la propuesta de aprender haciendo en un ambiente de interdisciplinariedad y crecimiento personal y grupal.

Otra característica de estos procesos es el denominado aprendizaje autorregulado, el cual exige acompañamiento y retroalimentación permanente, donde el rol del docente varía y es un supervisor y acompañante de los procesos de aprendizaje y autoevaluación que realiza el estudiante. 
Se considera también que la educación legal clínica promueve aprendizajes significativos porque los casos que se asumen implican una necesaria conexión con situaciones, experiencias y conocimientos previos y la necesidad de integrar los saberes.

Finalmente, consideramos que las clínicas responden al concepto de aprendizaje-servicio, que reúne dos propuestas: la acción comunitaria y solidaria (servicio) y los esfuerzos por aprender haciendo en un contexto de fortalecimiento del acceso a la justicia (Bloch, 2013).

Para la profesora Mascareño:

El servicio que las clínicas brindan a la comunidad y más específicamente a grupos sociales socialmente excluidos, reconociéndoles su derecho de acceso a la justicia, establece una valiosa relación entre la institución universitaria y la comunidad en la que está inserta, permitiendo que la universidad deje de considerarse como un centro formador de élites y sea reconocida como una institución progresista del bienestar social. La brecha entre derecho y realidad se va a acortar en la medida que el concepto de interés público se inserte en la esfera de la educación jurídica (Mascareño citado en Torres Villarreal, 2014).

Como elemento final de gran importancia, conviene incluir una reflexión sobre el concepto de aprendizaje-servicio, que desde los años noventa se plantea como un método por medio del cual se busca que los estudiantes o participantes aprendan, integren su currículo con actividades cívicas a través de servicios organizados en la comunidad, se involucren en la búsqueda de solución de problemas y reflexionen sobre dicha experiencia, que además deberá ser evaluada por la universidad. Algunas fundaciones le aportan elementos interesantes relacionados con el principio ético de este trabajo y lo denominan aprendizaje y servicio solidario, y se hace énfasis en un equilibrio entre el aprendizaje y el servicio.

\section{A manera de síntesis}

Se puede concluir que la educación legal clínica es un modelo en construcción a nivel internacional y que se ajusta a muchas de las nuevas exigencias de la Unesco. Se trata de una alternativa que fusiona las tres funciones misionales de la universidad: (i) extensión, con un enorme potencial social 
derivado del litigio estratégico; (ii) docencia, con muchos avances en la construcción de un modelo pedagógico innovador para el área y con grandes potencialidades para el desarrollo de investigación, y (iii) investigación, por su contribución en el fortalecimiento de competencias investigativas de los estudiantes.

De igual forma en este modelo se observan aportes en relación con procesos de formación integral, aprendizaje activo, aprendizaje constructivo, aprendizaje autorregulado, aprendizaje significativo y aprendizaje servicio.

\section{Investigación sobre el modelo pedagógico clínico realizada por las universidades de Medellín y de Chile}

La investigación presentada como avance en el encuentro de Santa Marta por las doctoras Erika Castro y Liliana Gallo (2012) tiene por objetivo analizar y comparar las líneas de intervención, criterios técnicos, programas y buenas prácticas existentes en las clínicas de Colombia, Chile y Argentina. A través de este proceso comparativo de la forma como se realiza la enseñanza clínica, se permiten contrastes y comparaciones, buenas prácticas y construcción de modelos.

En la definición de buenas prácticas se incluyen exigencias como la evidencia de mejora de procesos; la consistencia y coherencia entre planeación, objetivos y resultados; la innovación y la posibilidad de ser replicable.

En dicho trabajo se utiliza una metodología por dimensiones, las cuales son presentadas por las investigadoras:

a) Dimensión curricular. Análisis de los diferentes programas de las Facultades, la relación de su estructura curricular, perfiles de egreso. Educación desde el tema del proceso educativo.

b) Dimensión fáctica. Su objeto es analizar los aspectos prácticos de la clínica, funcionamiento, rol del docente, los estudiantes. Evaluación del aprendizaje de los estudiantes.

c) Dimensión institucional. Relación del contexto institucional con las clínicas.

d) Dimensión de contexto, que aborda los factores del contexto del país que influyen positivamente en el desarrollo de la enseñanza clínica (Castro, 2012). 
La doctora Castro considera que si bien ha existido una clara influencia de Estados Unidos en algunas clínicas, este modelo no es la referencia del trabajo de todas. En las investigaciones realizadas se observan escasas evidencias de entrenamiento de docentes clínicos, diseño de parámetros para la educación legal clínica y financiamiento. Nuestro modelo es diferente al norteamericano.

La aplicación de los instrumentos de investigación se realizó en cuatro universidades: Universidad de Medellín, Unisabaneta, upв y Universidad de Antioquia.

Algunos de los resultados iniciales fueron:

- Lineas de trabajo: se observa que no hay unificación temática.

- Apoyos institucionales: las clínicas trabajan muy solas, a pesar del reconocimiento público. Falta reconocimiento por parte de los programas académicos y las universidades.

- Currículo sobre clínicas jurídicas: no existe o se adapta y transforma.

- Construcción permanente de conocimiento real: no hay algo predefinido. Se va más allá de los conocimientos prácticos.

- El currículo oculto: las clínicas contribuyen a la convivencia, nuevas normas y prácticas sociales nuevas; permiten relaciones entre sujetos (docente, discente, comunidad educativa).

- Apoyo docente para las clinicas: se observa que hay articulación entre el trabajo del docente y los estudiantes. A veces recae en un solo docente.

- Herramienta de enseñanza: espacio aun no reconocido por las facultades.

¿Cómo puede incluirse la clínica en el currículo de las facultades de derecho? El siguiente cuadro resume algunas de las características de los modelos curriculares de clínicas universitarias existentes en América Latina: 
Tabla 7. Modelos curriculares de algunas clínicas jurídicas examinadas

\begin{tabular}{|c|c|c|c|c|}
\hline $\begin{array}{c}\text { Modelos- } \\
\text { características }\end{array}$ & $\begin{array}{l}\text { Asignatura } \\
\text { obligatoria }\end{array}$ & $\begin{array}{l}\text { Asignatura electiva } \\
\text { en los dos últimos } \\
\text { años }\end{array}$ & $\begin{array}{l}\text { Actividad } \\
\text { voluntaria }\end{array}$ & $\begin{array}{c}\text { Práctica alternativa } \\
\text { o complementaria } \\
\text { del consultorio } \\
\text { jurídico o servicio } \\
\text { social }\end{array}$ \\
\hline $\begin{array}{l}\text { Ejemplo de } \\
\text { facultades de } \\
\text { derecho que lo } \\
\text { ofrecen }\end{array}$ & $\begin{array}{l}\text { Universidad } \\
\text { Torcuato di Tella } \\
\text { (Argentina), } \\
\text { Unisabaneta } \\
\text { (Colombia). }\end{array}$ & $\begin{array}{l}\text { Universidad } \\
\text { Diego Portales, } \\
\text { Universidad } \\
\text { de Palermo } \\
\text { (Argentina). }\end{array}$ & $\begin{array}{l}\text { Universidad } \\
\text { de Medellín } \\
\text { (Colombia), } \\
\text { Universidad } \\
\text { Manuela Beltrán- } \\
\text { Proyecto Inocencia } \\
\text { (Colombia), } \\
\text { Universidad de } \\
\text { los Andes-PAIIs } \\
\text { (Colombia). }\end{array}$ & $\begin{array}{l}\text { U. Córdoba, UBA } \\
\text { (Argentina), } \\
\text { Universidad del } \\
\text { Rosario, Icesi, } \\
\text { Universidad de Los } \\
\text { Andes. Área de } \\
\text { Justicia Colectiva } \\
\text { (Colombia). } \\
\text { Universidad } \\
\text { Sergio Arboleda } \\
\text { (Colombia). }\end{array}$ \\
\hline $\begin{array}{l}\text { Duración de la } \\
\text { clínica }\end{array}$ & Un semestre. & Un semestre. & $\begin{array}{l}\text { Elegida por los } \\
\text { estudiantes. }\end{array}$ & Dos semestres. \\
\hline Ventajas & $\begin{array}{l}\text { - Mayor número } \\
\text { de estudiantes. } \\
\text { - Apoyo } \\
\text { institucional. } \\
\text { - Muchos } \\
\text { estudiantes } \\
\text { tienen } \\
\text { oportunidad de } \\
\text { participar en } \\
\text { las clínicas. }\end{array}$ & $\begin{array}{l}\text { - El estudiante } \\
\text { elige el tema } \\
\text { en el que desea } \\
\text { trabajar. } \\
\text { - Apoyo } \\
\text { institucional. } \\
\text { - Muchos } \\
\text { estudiantes } \\
\text { tienen } \\
\text { oportunidad de } \\
\text { participar en } \\
\text { las clínicas. } \\
\text { - Flexibilidad. }\end{array}$ & 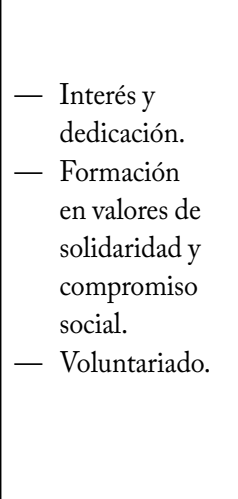 & $\begin{array}{l}\text { - Menor número } \\
\text { de estudiantes } \\
\text { que se eligen } \\
\text { cuidadosamente } \\
\text { para la labor a } \\
\text { desarrollar. } \\
\text { — En el caso de } \\
\text { las clínicas } \\
\text { argentinas es } \\
\text { importante el } \\
\text { apoyo de las } \\
\text { ong. }\end{array}$ \\
\hline Desventajas & $\begin{array}{l}\text { - Gran carga } \\
\text { para un } \\
\text { docente clínico } \\
\text { sin apoyo de } \\
\text { supervisores } \\
\text { - Limitaciones } \\
\text { de tiempo } \\
\text { para el trabajo } \\
\text { clínico. } \\
\text { - Escasa } \\
\text { continuidad en } \\
\text { el seguimiento } \\
\text { de casos. }\end{array}$ & $\begin{array}{l}\text { - Gran carga } \\
\text { para un } \\
\text { docente clínico } \\
\text { sin apoyo de } \\
\text { supervisores. } \\
\text { - Limitaciones } \\
\text { de tiempo } \\
\text { para el trabajo } \\
\text { clínico. }\end{array}$ & $\begin{array}{l}\text { - Carencia de } \\
\text { valoración } \\
\text { académica para } \\
\text { tan importante } \\
\text { escenario de } \\
\text { formación. } \\
\text { - Falta de apoyo } \\
\text { institucional. }\end{array}$ & $\begin{array}{l}\text { - Escasa } \\
\text { valoración } \\
\text { académica de } \\
\text { este importante } \\
\text { escenario de } \\
\text { formación. } \\
\text { - Dificultades } \\
\text { para armonizar } \\
\text { el modelo con } \\
\text { el trabajo de } \\
\text { los consultorios } \\
\text { jurídicos } \\
\text { o servicios } \\
\text { sociales. }\end{array}$ \\
\hline
\end{tabular}

Continúa 


\begin{tabular}{|l|l|l|l|l|}
\hline $\begin{array}{c}\text { Modelos- } \\
\text { características }\end{array}$ & $\begin{array}{c}\text { Asignatura } \\
\text { obligatoria }\end{array}$ & $\begin{array}{c}\text { Asignatura electiva } \\
\text { en los dos últimos } \\
\text { años }\end{array}$ & $\begin{array}{l}\text { Actividad } \\
\text { voluntaria }\end{array}$ & $\begin{array}{l}\text { Práctica alternativa } \\
\text { o complementaria } \\
\text { del consultorio } \\
\text { jurídico o servicio } \\
\text { social }\end{array}$ \\
\hline $\begin{array}{l}\text { Integración } \\
\text { con la } \\
\text { estructura } \\
\text { curricular }\end{array}$ & $\begin{array}{l}\text { Clara y con } \\
\text { valoración } \\
\text { académica. }\end{array}$ & $\begin{array}{l}\text { Clara y con } \\
\text { valoración } \\
\text { académica. }\end{array}$ & $\begin{array}{l}\text { Sin valoración } \\
\text { académica. }\end{array}$ & $\begin{array}{l}\text { Se valora como } \\
\text { práctica pero no } \\
\text { tiene claridad en } \\
\text { materia de créditos } \\
\text { académicos. }\end{array}$ \\
\hline $\begin{array}{l}\text { Número de } \\
\text { docentes } \\
\text { clínicos }\end{array}$ & $\begin{array}{l}\text { Un profesor para } \\
\text { cada clínica. }\end{array}$ & $\begin{array}{l}\text { Un profesor para } \\
\text { cada clínica. }\end{array}$ & $\begin{array}{l}\text { Varios docentes } \\
\text { voluntarios que } \\
\text { supervisan. }\end{array}$ & $\begin{array}{l}\text { Varios docentes } \\
\text { asignados a la } \\
\text { práctica en calidad } \\
\text { de supervisores. }\end{array}$ \\
\hline $\begin{array}{l}\text { Evaluación } \\
\text { asignatura, pero }\end{array}$ & $\begin{array}{l}\text { Similar a otra } \\
\text { asignatura, pero } \\
\text { basada en los } \\
\text { trabajos. }\end{array}$ & $\begin{array}{l}\text { Sin evaluación } \\
\text { académica, pero } \\
\text { con evaluación } \\
\text { interna. }\end{array}$ & $\begin{array}{l}\text { Evaluación de } \\
\text { aprobación o no } \\
\text { del trabajo basada } \\
\text { en criterios de la } \\
\text { práctica clínica. }\end{array}$ \\
\hline $\begin{array}{l}\text { Nivel de } \\
\text { impacto } \\
\text { curricular }\end{array}$ & Alto. & Alto. & Sin impacto. & Bajo. \\
\hline $\begin{array}{l}\text { Respaldo } \\
\text { institucional }\end{array}$ & Alto. & Alto. & Variable. & Variable. \\
\hline
\end{tabular}

Fuente: elaboración propia.

El debate con las autoridades académicas —especialmente rectores y decanos- es urgente, porque los cambios requieren toma de decisiones claras, impulso y recursos para su sostenibilidad. A manera de ejemplo, podemos referenciar el intento que se realizó en Centroamérica. En el año 2001 se realizó en El Salvador la Primera Conferencia Centroamericana sobre el Uso de Clínicas y Pasantías en la Enseñanza Universitaria del Derecho, cuyo objetivo era "tratar de introducir el concepto de educación clínica" (Álvarez, 2005, p. 69). Los riesgos evidenciados en dicho ejercicio no difieren mucho de los que hoy se identifican por los docentes clínicos en Iberoamérica (Álvarez, 2005, pp. 72-73):

- La tentación de llamar clínicas a estos centros pero que no funcionen como tales: 
Mi recomendación a los decanos y otras autoridades con poder en las facultades de derecho es que aprendan el modelo, y que no se dejen llevar por la tentación de llamarlas clínicas sin comprometerse con el trabajo necesario para que verdaderamente funcionen como clínicas. Las clínicas deben aceptar el número de estudiantes que se puedan supervisar bien (Álvarez, 2005, p. 74).

- Presión de tener muchos estudiantes y pocos docentes clínicos. "Si hay demasiados estudiantes por clínica, no van a llevar los casos, o no van a recibir el apoyo que necesitan para aprender y hacer un buen trabajo" (Álvarez, 2005, p. 72).

- Carencia de recursos por parte de las universidades.

- "La otra tentación es ver la clínica como cualquier otra materia, que requiere la misma inversión de tiempo por parte del docente"; en la práctica sabemos que los docentes clínicos dedican mucho más tiempo a su trabajo, porque la supervisión implica trabajo personal altamente técnico y cuidadoso con los estudiantes (Álvarez, 2005, p. 72).

- Carencia de casos para la clínica. Es importante tener redes de referencia y alianzas con ONG.

- La contabilización de las horas en trabajo clínico y su equivalencia en créditos. En este tema coinciden los planteamientos de los docentes clínicos y los estudiantes.

- Falta de espacios de formación para docentes clínicos. "Los docentes de estas clínicas necesitan adquirir las destrezas de profesores de clínicas. Esto implica no solo las destrezas del abogado (entrevistar, planificar, asesorar, negociar y destrezas de oralidad) sino también las destrezas de cómo enseñar, incluyendo como hacer la retroalimentación".

- Trabajo común de los profesores de las diversas clínicas:

Primero, hay que buscar la manera de crear conexiones entre los profesores de las diferentes clínicas. De esta forma pueden aprender unos de otros [...]. Es importante también establecer relaciones con otros profesores de clínicas jurídicas en Centroamérica y Latinoamérica. También tienen que buscar la forma de aprender las destrezas 
necesarias para ser no solo un buen abogado, sino también un buen docente (Álvarez, 2005, p. 72).

- El reto de adaptar el modelo de clínicas a la realidad nacional y regional y el de crear capacidad interna para que pueda subsistir.

La opción que se elija en materia de fortalecimiento de competencias e institucional se encuentra ligada al modelo clínico por el cual se opta, es decir, si se trata de un modelo clínico de enseñanza aprendizaje con énfasis en investigación, o de las competencias referidas a la identificación y análisis de problemas, o de la utilización de técnicas de investigación, así como las de análisis crítico, lectura y escritura. Si el modelo opta por litigio estratégico, las competencias profesionales de observación, análisis de caso, atención de usuarios, participación en audiencias públicas, oratoria, escritura de documentos especializados, fortalezas en materia procesal, serán las definitivas. De igual forma se puede optar por un modelo clínico basado en aprendizaje-servicio y en este será necesario fortalecer competencias de relacionamiento con la comunidad y competencias pedagógicas. En cualquiera de los modelos se deben fortalecer competencias éticas y ciudadanas.

\section{Logros y dificultades de la educación legal clínica en América Latina}

Los docentes clínicos latinoamericanos tienen mucho que aportar y cada uno, en el campo de su trabajo, señala avances muy valiosos. En esta sección trataremos solo de sistematizar los aportes de las entrevistas logradas con los profesores.

\section{El posicionamiento académico, social y político de los temas de trabajo de las} clínicas

Es el primer avance común que encontramos. Veamos algunos casos.

Para la clínica de migrantes de la Universidad Diego Portales, lo más importante ha sido "lograr posicionarse como un referente en materia de atención clínica a inmigrantes y ser reconocida por los otros actores sociales del tema [...]. Es un referente para la comunidad de inmigrantes de Chile" (Olea, 2013). De igual forma el reconocimiento institucional es un avance que destacan los profesores: "lo más importante ha sido la estabilidad y el reconocimiento. Existe una ubicación, reconocimiento externo, difusión, un grupo 
de trabajo. La clínica es conocida por los estudiantes y por las organizaciones sociales que buscan sus servicios"(García Añón, 2013a).

Los resultados en materia de derechos humanos son de gran magnitud y cuando una clínica puede afirmar que gracias a su trabajo en coordinación con muchos actores, "se acabaron las expulsiones masivas de extranjeros en Argentina” o se logró "agua para 7 barrios de la localidad de Ciudad Bolívar en Bogotá - Colombia”, es necesario reconocer el gran potencial de este trabajo que en muchos países pasa desapercibido.

En relación con el posicionamiento jurídico, se destaca cómo a través del litigio en casos de violación de derechos humanos, derechos ambientales, sociales, colectivos y garantías constitucionales, se ha contribuido al fortalecimiento de una jurisprudencia latinoamericana y a la generación de precedentes en temas que jamás llegarían a los jueces o tribunales sin el ejercicio de las clínicas y las ONG.

Otra forma de actuación muy valiosa ha sido el lobby legislativo para impulsar normas que amplíen la protección de derechos humanos (como en el caso de la ley argentina de migrantes) y también la incidencia de los amicus curiae en el sistema interamericano de derechos humanos.

La incidencia o impacto público de las clínicas iberoamericanas, además del litigio en tribunales, se observa en aspectos como la producción de informes de derechos humanos, la elaboración y difusión de amicus curiae en casos de gran interés. Gracias a los medios de comunicación y las redes sociales, las clínicas logran llegar a un mayor número de personas necesitadas de protección y acompañamiento jurídico y crecen las peticiones de organizaciones de la sociedad e incluso de entidades públicas, como los ayuntamientos o alcaldías (Galiana Saura, 2013).

Incidencia legislativa en el surgimiento de nuevas normas que garanticen los derechos humanos o derechos de grupos de especial protección;

La incidencia en el futuro profesional de los estudiantes. De igual forma, reconocen los profesores la incidencia de las clínicas en el futuro profesional de los estudiantes que participan: "la clínica incide. Es la primera vez que se enfrentan ante supuestos reales. Los casos les exigen entrar en la vida práctica y asumir nuevas responsabilidades" (Galiana Saura, 2013).

Para la profesora Olea, la clínica es indudablemente "una buena experiencia según lo que las evaluaciones dicen y además les permite reencantarse con el derecho [...] en la experiencia del litigio estratégico los estudiantes 
descubren algo que les interesa mucho, parece que descubren las virtudes del trabajo profesional y del trabajo de casos y contrastan con lo que ven en teoría"(Olea, 2013).

Cambios en la docencia universitaria. En algunas universidades se ha logrado la inclusión de la clínica en la malla curricular y en ellas constituye un gran avance y permite mayor visibilidad y respeto por la educación legal clínica en las facultades de derecho, pero, independientemente de la inclusión curricular o no, se evidencian transformaciones en la docencia universitaria en muchas de las universidades que han iniciado experiencias de educación legal clínica.

Los docentes clínicos han promovido nuevas maestrías y doctorados al interior de sus universidades y generalmente están vinculados con propuestas de revistas y publicaciones que permiten continuar los debates e incorporar nuevas visiones de los problemas.

En otras clínicas, como la de la Universidad de Medellín, se considera un gran logro "la reflexión realizada sobre cómo hacer una metodología de investigación jurídica en materia ambiental, que sea novedosa y pueda ser replicada en otras universidades de la región" (Castro Buitrago, 2006).

La labor de educación legal clínica empieza a recibir reconocimientos. Por ejemplo la Clínica de la Universidad Rovira i Virgili, de Tarragona, recientemente recibió varios reconocimientos por medio de diferentes proyectos competitivos de innovación docente (2012PID-UB/031) y de divulgación de los resultados de la investigación (2012ACDC-0004) (Galiana Saura, 2013).

Impulso al trabajo en derechos humanos y surgimiento de nuevas clinicas. En el caso del cELs se destaca por su director "la existencia de un trabajo consolidado en derechos humanos y el impulso de nuevas clínicas temáticas y clínicas en las provincias de Argentina, especialmente las de Neuquen y Jujuy”.

Lentamente se avanza en la interdisciplinariedad porque los temas lo exigen. Ello es evidente en las clínicas ambientales, en las de migrantes y en las de discapacidad.

La renovación generacional. Las clínicas han permitido un relevo generacional en las universidades, muchas clínicas son verdaderas escuelas de nuevos docentes; al respecto Mariela Puga indica que: "las clínicas han sido un semillero de formación de profesores en América Latina. No se ha medido su impacto"(2012).

En la mayoría de las clínicas iberoamericanas, los mejores alumnos asumen luego roles de coordinación. Esto ha sucedido por ejemplo en el cELS, 
en la clínica cels-Caref, en la Clínica de la Universidad de Palermo, en la Universidad del Rosario, en la Universidad de Medellín, en la Universidad San Marcos, en la Universidad de Tarragona, entre muchos ejemplos que pueden mencionarse.

También se destaca que en algunas clínicas, como las de Valencia y la Universidad del Rosario, existen oNG integradas por exalumnos que continúan trabajando en derechos humanos.

La integración de docentes de diferentes áreas. Este logro se evidencia en la Universidad de Barcelona (Madrid, 2013). En esta universidad tienen una clínica constituida por docentes del área de derecho civil, pero trabajan todas las áreas. También existe esta integración de áreas en la Universidad de Valencia y los docentes apoyan como tutores los casos de su especialidad.

Estos equipos de docentes existen también en la Universidad Católica del Perú: "la clínica jurídica está organizada a partir de un equipo de profesores del Departamento de Derecho que son seleccionados en función de las especialidades que se deciden para el semestre"19.

Las alianzas para el manejo de los casos. Se observa una gran capacidad de interrelación y trabajo interinstitucional en la mayoría de las clínicas iberoamericanas. Este aprendizaje fortalece el ejercicio del litigio estratégico pero también otro tipo de actividades, como la difusión y la labor pedagógica. En algunos países las clínicas han desarrollado igualmente trabajo de capacitación a jueces, magistrados y servidores públicos.

En estas alianzas es muy fuerte el apoyo desde las ONG en su compromiso de continuar, aunque existan muchos obstáculos, por ejemplo en México: “el litigio de interés público se ha realizado por organizaciones de la sociedad civil, aunque tampoco hay mucho, cada vez más las organizaciones incorporan un componente de litigio estratégico" (Rodríguez, 2013).

Alianzas para proyectos de investigación. Un ejemplo interesante lo presentan las cuatro clínicas que hay en España, al formar parte de un proyecto de investigación en materia de migrantes.

Existe un debate interesante en relación con las alianzas norte-sur, planteado por el profesor Daniel Bonilla, ${ }^{20}$ quien reconoce importantes avances

\footnotetext{
$19 \mathrm{http} / / /$ facultad.pucp.edu.pe/derecho/index.php?option=com_content\&task=view\&id=419\&Ite mid=110\#.UUo0yBxhVJd

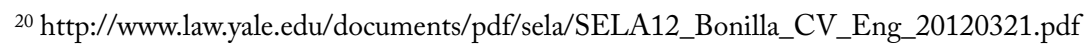


en materia de intercambios solidarios en búsqueda de solución de problemas de las comunidades más vulnerables, con servicios jurídicos de calidad y con alto impacto, sin embargo, estima que estos intercambios no deben reproducir sistemas verticales de relacionamiento centro-periferia, porque se desvirtúan los propósitos del trabajo en derechos humanos.

La constitución de la Red Latinoamericana de Clínicas Jurídicas. Para la mayoría de los profesores entrevistados, la Red Latinoamericana es uno de los mayores logros de las clínicas en la región, pero a su vez es uno de los retos a enfrentar.

El trabajo de Castro-Buitrago et ál., le da a este periodo la denominación de "segunda generación del movimiento por el derecho y el desarrollo" y se presenta la Red como uno de sus mayores logros (2013, p. 138).

Según relata González (2004, pp. 15 y ss.) la Red Sudamericana surge en el año 1997, en el marco de un proyecto piloto que coordinaba la Universidad Diego Portales. Inicialmente se circunscribió a Chile (Universidad Diego Portales, Universidad Católica de Temuco), Argentina (Universidad de Buenos Aires y Universidad de Palermo) y Perú (Pontificia Universidad Católica del Perú y Universidad de San Agustín, en Arequipa), pero luego ingresaron clínicas de México (ITAm y cide) y Colombia (Universidad del Rosario y Universidad de Los Andes).

El gran impulso de la Red fue dado por la Universidad Diego Portales en Chile y por el CELS-UBA en Argentina. Inicialmente se integran a la Red facultades de Chile, Argentina, Perú y Colombia; luego crece el grupo de países integrantes.

El tema central de esta red ha sido el derecho de interés público. "Así las clínicas jurídicas de interés público comenzaron a operar bajo la lógica del litigio estratégico, tratando de conectar las facultades de derecho con las cuestiones sociales y los nuevos desafíos dogmáticos de la teoría del derecho" (Castro Buitrago, 2006, p. 139).

Un elemento fundamental a destacar han sido los encuentros internacionales:

En este proceso de estructuración de las clínicas de interés público también han jugado un papel significativo las instancias de encuentro. Así, durante el primer lustro de funcionamiento de la Red se efectuaron anualmente dos encuentros de clínicas de interés público por 


\begin{abstract}
país, además de un Seminario y Encuentro Internacional de clínicas anual. El primer encuentro nacional en cada país estuvo dedicado en una proporción importante a discutir aspectos organizacionales y de formas de trabajo de las clínicas. Luego estos encuentros estuvieron dedicados de manera preferente a la presentación de casos por los propios alumnos, discutiéndose el interés público envuelto en ellos y las estrategias jurídicas y comunicacionales (para producir un impacto público), sin perjuicio de que, con ocasión de dichos encuentros, se hayan realizado también foros de discusión, presentaciones de especialistas y hasta lanzamientos de publicaciones de la Red (Castro Buitrago, 206, p. 140).
\end{abstract}

Se trata de oportunidades de aprendizaje, debate y aporte a casos en construcción y análisis de avances investigativos sobre los temas de la educación legal clínica y el litigio estratégico.

Se reconocen avances con los encuentros de la Red, en especial el realizado en 2005 en Chile y luego en Tucumán, Argentina. Luego la reunión de México en 2007 con participación de clínicas del continente, incluyendo algunas de Estados Unidos. En 2008, la Universidad Torcuato di Tella citó a una reunión de la Red en Argentina buscando colaboración en litigios internacionales ante la Corte Interamericana. En 2009 se realizó en Colombia la reunión de la Red y fue convocada por las Universidades de Los Andes, Sergio Arboleda y Rosario, en Bogotá, y en 2014 se convocó nuevamente en Colombia, en la Universidad del Rosario, con el objetivo de fortalecer la red a través de una declaración conjunta (ver anexo 3) y la constitución de una secretaría técnica elegida en forma democrática e integrada por el cels (Argentina), la Universidad Diego Portales (Chile), El iтам (México), la Universidad de Medellín y la Universidad del Rosario (Colombia). En dicho encuentro se reafirmaron sus objetivos y aportes:

El objetivo de esta red es fortalecer la enseñanza clínica y a través de este instrumento intervenir en la defensa del interés público y los derechos humanos mediante el litigio estratégico como herramienta. La Red ha generado cambios significativos en la docencia e investigación jurídica en América Latina y su integración garantiza la participación de docentes y estudiantes en la propuesta, desarrollo 
y evaluación de las causas de interés público que adelanta (Clínicas Jurídicas, 2013).

Las clínicas pertenecientes a esta red se han caracterizado porque: (i) su eje de trabajo lo constituyen el interés público, la justicia social y el respeto por los derechos humanos; (ii) la búsqueda de cambio social estructural a través del litigio estratégico y el activismo legal; (iii) proyectos conjuntos que relacionan a las universidades con organizaciones de la sociedad civil, y (iv) su creatividad en el desarrollo de propuestas de intervención judicial.

En el marco de la Red han surgido muchas clínicas en la región, y se promueven casos y aprendizajes conjuntos. De igual forma se realizó una labor de formación práctica de docentes y en algunos encuentros, como el de Tucumán, se trabajaron temas centrales, como el de los desafíos de la supervisión al interior de las clínicas. Otros aspectos centrales de la Red han sido el relacionamiento, la mirada regional de los problemas, los aportes de los docentes y el espacio compartido con los estudiantes de las clínicas, donde en cada encuentro se presentaban los mejores casos y se debatían estrategias, logros y dificultades.

\section{Las dificultades en la educación legal clínica iberoamericana}

Frente al reto de iniciar y fortalecer propuestas de educación legal clínica, son muchos los obstáculos que han tenido que enfrentar las clínicas iberoamericanas; los principales problemas que se evidencian de las entrevistas y las encuestas realizadas son los siguientes.

\section{Dificultades en la sostenibilidad de las clinicas}

Muchos obstáculos que impiden la sostenibilidad de las clínicas, por ejemplo, la carencia de recursos, carencia de docentes clínicos, exigencia de recibir un alto número de estudiantes, cuando este método tiene unos límites en el número de participantes por curso, además, como lo sostiene Grandez, "El tema de clínicas jurídicas exige un presupuesto, demanda más tiempo, más responsabilidades de más personas, más horas del profesor de curso" (2013).

Los docentes clínicos iberoamericanos hacen mucho énfasis en la necesidad de que se reconozcan las horas de clínica como trabajo de docencia directa. Es muy baja la dedicación en horas al trabajo clínico y en pocas universidades hay reconocimiento de dicha actividad en el plan de trabajo. Los profesores 
clínicos son externos y dada la labor que desarrollan, las universidades deberían repensar esta categoría e incluirlos en sus estatutos profesorales o en su planta en forma permanente. Además, en muchas universidades existe un abismo generacional y de pensamiento pedagógico entre los docentes clínicos y los demás profesores.

El trabajo de educación legal clínica exige espacios adecuados, salones de reunión donde se trabaje en forma horizontal y se disponga de ayudas audiovisuales. De igual forma se requiere de espacio adecuado para la atención de usuarios.

Otro de los problemas tiene que ver con el escaso reconocimiento por el trabajo clínico. Los programas de derecho deben repensar su papel en la enseñanza y en la práctica profesional. Una estrategia interesante por medio de la cual se han logrado recursos en algunas clínicas ha sido la de participar en las convocatorias de innovación docente. La Universidad de Barcelona y la de Tarragona han logrado recursos de apoyo a sus clínicas por esta vía.

No solo existen dificultades internas para iniciar procesos de educación legal clínica, sino para mantenerlos en el tiempo. Hemos visto cómo han desaparecido varias clínicas jurídicas en países como México, Argentina y Colombia, entre otras razones por "la reticencia desde las universidades a establecer clínicas de derechos humanos, por las cuestiones políticas e ideológicas que temen enfrentar" (Rodríguez, 2013).

También se señala como un problema grave la carencia de espacios de debate y formación sobre los nuevos paradigmas en la enseñanza y ejercicio del derecho. Se carece igualmente de publicaciones, sitios web y otros medios que permitan formar nuevos docentes clínicos y supervisores en las clínicas (González Morales, 2013).

Son pocas las clínicas que tienen una ubicación organizacional clara como departamento o similares. En su mayoría dependen de las decanaturas como proyectos especiales o de los consultorios jurídicos o servicios de asistencia social. Un intento muy interesante que han logrado clínicas como la de Valencia es convertir la clínica en un espacio de apoyo trasversal de las diversas áreas académicas de la facultad.

No hay tampoco recursos suficientes para la participación en redes de clínicas. Este elemento es vital, porque las redes son espacios de aprendizaje e interacción vitales. 
En países como España y Argentina, se considera un obstáculo la presión que ejercen los colegios de abogados para que no se constituyan nuevas clínicas. De igual forma existen trabas en los ayuntamientos para dar información, especialmente en el tema de licencias ambientales y urbanísticas.

Otra dificultad frecuente se relaciona con el manejo de los casos de las clínicas y su impacto en términos políticos y mediáticos. Las clínicas se acabaron, no porque no fueran buenas clínicas, sino por decisiones de las rectorías.

En varios trabajos se ha señalado como un grave problema la falta de visibilidad de las clínicas y de su propuesta pedagógica. Esta característica ha sido estudiada en trabajos como el de Puga (2012). Se concluye en ellos que esta es una de las debilidades en la gran mayoría de las clínicas iberoamericanas. En muchas ocasiones la búsqueda de las clínicas por internet es imposible, no hay resultados; en otras solo se llega a un breve párrafo genérico sin información sustancial. Las universidades no han dimensionado la importancia de una verdadera estrategia de medios y redes sociales para visibilidad las clínicas.

\section{Dificultades externas}

Para las clínicas es de gran importancia su relación con el medio y su incidencia externa. Como dificultades al respecto se señalan las siguientes:

- El trabajo realizado no se perfila en muchos casos como generador de jurisprudencia. Las clínicas tienen dificultades para lograr incidencia jurídica y judicial.

- Otro problema que se presenta es la manipulación de la información por parte de los medios de comunicación en casos de interés público. Se desvirtúa o minimiza el resultado del trabajo. En algunos casos, incluso, se ataca el proceso de formación en las clínicas y su enorme valor.

- En España y Argentina se presentan problemas con los colegios de abogados, los cuales alegan que el asesoramiento gratuito es ilegal y genera competencia desleal de las clínicas con los bufetes de abogados. Este desconocimiento de la educación legal clínica requiere de intervención urgente, especialmente desde las instancias administrativas y de autorregulación de la profesión. Igualmente las fundaciones pro bono en cada país deberían buscar cambios urgentes y trabajo de apoyo y no de ataque a las clínicas (Puga, 2012). 
- En algunos países se evidencian problemas para la inserción laboral de los estudiantes egresados a pesar de sus conocimientos en el tema de la clínica.

- La carencia de recursos financieros ha afectado especialmente a las oNG que apoyan a las universidades en educación legal clínica. Hay pocos recursos, los fondos son cada vez más reducidos e implican redefiniciones.

En el caso chileno, se plantean las siguientes críticas a la labor de las clínicas jurídicas:

Pocos de estos programas han sido capaces de alejarse de las principales características de la cultura jurídica chilena: principalmente positivista respecto a las fuentes del derecho, en la interpretación formalista de dichas fuentes, y legalista en su comprensión de la función del papel que el ordenamiento desempeña en el desarrollo de la vida colectiva [...]. De igual forma se estima que las clínicas jurídicas han permanecido al margen del proceso de transformación de la cultura y la educación jurídica chilena (Castro-Buitrago, 2013, p. 147).

En relación con Argentina, se señala que: "las facultades públicas de derecho, que tienden a tener más prestigio que las facultades de derecho privadas en Argentina, han sido especialmente reacias a implementar innovaciones curriculares, en particular respecto de los nuevos métodos pedagógicos en la enseñanza del derecho" (Castro-Buitrago, 2013, p. 140). Esta constatación se puede generalizar a América Latina. Sin embargo, en el caso de España y Perú, las universidades públicas son ahora las protagonistas.

Para finalizar se pueden señalar otros problemas en las clínicas en Iberoamérica, como los siguientes: (i) se centran en trabajo interno, doméstico o nacional; (ii) no se ha desarrollado una agenda regional de trabajo para las clínicas; (iii) falta repensar el papel de las clínicas en la enseñanza y en la práctica profesional; (iv) son escasos los esfuerzos de documentación de las experiencias pedagógicas y de litigio de las clínicas, aunque ya se empieza a tener alguna bibliografía; (v) no hay continuidad en el fortalecimiento de las redes y, finalmente, (vi) la incidencia en la reforma educativa es muy baja y a veces inexistente (Castro-Buitrago, 2013, p. 139). 